\title{
The Effect of Local Area Crime on Mental Health
}

\author{
April 2014 \\ Christian Dustmann \\ Department of Economics, University College London and CReAM \\ Francesco Fasani \\ School of Economics and Finance, Queen Mary - University of London, CREAM and IZA
}

\begin{abstract}
This paper analyses the effect of local crime rates on the mental well-being of residents. Our identification strategy addresses the problem of sorting, and endogenous moving behaviour. We find that crime causes considerable mental distress of residents, and that these effects are mainly driven by property crime. However, individuals react also to violent crime, in particular in areas individuals may be exposed to when following their daily routines, such as travel to work. Local crime creates more distress for females, and is mainly related to depression and anxiety. The impact on mental well-being is large: We find that the increase in mental distress following a one standard deviation increase in local crime is about 2-4 times as large as that caused by a one standard deviation decrease in local employment, and about one seventh of the effect experienced by Londoners in the direct aftermath of the London Bombings of July $7^{\text {th }}, 2005$.
\end{abstract}

JEL Codes: I18, K42, R23

Keywords: neighbourhood effects, mental wellbeing, fear of crime

We are grateful to David Card, Francesca Cornaglia, Thomas Cornelissen, Guglielmo Weber, an editor and two anonymous referees for comments and suggestions. We would like to thank participants in conferences, workshops and seminars at IAE-CSIC (Barcelona), University of Milan Bicocca, Collegio Carlo Alberto (Turin), University of Alicante and EUI (Fiesole). We acknowledge financial support from the UK Economic and Social Research Council ("Crime and mental wellbeing"; grant number: RES-000-22-1979). Fasani acknowledges the financial support of INSIDE-MOVE (Markets, Organizations and Votes in Economics), the Barcelona GSE Research Network, the Government of Catalonia (grant 2009 SGR 896), the JAE-Doc grant for the Program "Junta para la Ampliación de Estudios" co-financed by the European Social Fund and the Spanish Ministry of Science (grant ECO2011-25293). Dustmann acknowledges funding by the Norface programme on migration. Corresponding author: F. Fasani, Department of Economics and Finance, Queen Mary, 327 Mile End Road, E1 4NS, London (UK); telephone: +44 0207882 5869; email: f.fasani@qmul.ac.uk. The usual disclaimer applies. 


\section{Introduction}

According to the Eurobarometer, crime has been among the top five concerns of European citizens in recent years, and the fight against crime is among the main priorities respondents believe their governments should have. ${ }^{1}$ These concerns seem hardly justified by actual crime rates, where European countries rank very low in comparison to other parts of the world, ${ }^{2}$ which suggests that crime leads to distress for a large part of the population through channels other than direct victimisation. These indirect costs of crime, through inflicting fear and anxiety, and leading to changes in daily routines and behaviour (see e.g. Hamermesh, 1999; Braakman, 2013; Janke et al., 2013), may be far larger than the direct costs. Indeed, in a recent paper, Gary Becker and Yona Rubinstein (2011) argue that major criminal acts such as terrorist attacks inflict most harm by creating fear, and by inducing changes in behaviour and individual choices. Measuring the magnitude of these indirect costs of crime is crucial for assessing the optimal investment into crime prevention. While the direct costs (response costs of police and the Criminal Justice System, and costs through the impact on victims) are routinely assessed ${ }^{3}$, evaluations of indirect costs, including those of non-victims, are scarce, and far more difficult.

In this paper we analyse costs of crime that are indirect and intangible. While indirect but tangible costs - such as changes in behaviour (not going out at night, not wearing jewellery, carrying a selfdefence weapon, etc.) and investment in security (burglar alarms, armoured doors and windows, weapons, etc.) - can in principle be inferred from surveys, intangible costs (fear, anxiety, mental distress, etc.) are particularly difficult to measure. Our main contribution is to estimate the effect

\footnotetext{
1 Summary reports on Eurobarometer waves since 1974 can be downloaded at: http://ec.europa.eu/public opinion/archives/eb arch en.htm.

${ }^{2}$ For instance, over the last decade, EU27 countries experienced a homicide rate below 2 per 100 thousand population, which contrasts with a world estimate of almost 8 (estimated in 2004) and with average rates in Southern Africa and Central America between 20 and 30 (Harrendorf et al. 2010).

${ }^{3}$ See Soares (2010) for a recent survey of the different approaches to estimating costs of crime. In its most recent estimation, the UK Home Office puts the cost of crime against individuals and households in the UK at about $£ 36.2$ bn in 2003/04, which amounts to about 3 percent of GDP (Dubourg et al, 2005). Following the methodology suggested in Dolan et al. (2005), these estimates carefully appraise "Physical and emotional impact on direct victims" - which accounts for about 50 percent of total cost of crime. However, they do not consider the additional cost imposed by the fear of crime on the overall British society, which is one objective of this paper.
} 
local crime has on the mental health of individuals who live in the area where this crime takes place, by combining official crime statistics with detailed information on individuals' mental well-being, which we obtain from the British Household Panel Survey (BHPS) and the English Longitudinal Study of Ageing (ELSA). Both these surveys are panel surveys, which allows us to use a design that eliminates possible correlation between area crime and mental distress due to sorting of more distressed individuals into areas with higher (or lower) crime incidences. By matching each individual to detailed local-area crime statistics for various types of crimes we are able to distinguish further between the effects that particular types of crime have on mental health, thus identifying the most distressing criminal offences. We also analyse the impact of crime on different dimensions of mental health, and we study heterogeneity in responses across different groups of residents.

Our findings show a significant, and negative, impact of overall local crime rates on the mental distress of residents in urban areas. The impact is sizeable: a one standard deviation in the overall local crime rate explains between 8-15 percent of the (within-individual) standard deviation in selfreported mental wellbeing. This is about twice to four times as large as the effect of a one standard deviation decrease in the areas' employment rate on mental distress. Burglary, car theft and vandalism are the crime types which seem to cause major anguish. In addition, we find heterogeneity in responses. While individuals react only to property crime when crime rates are measured in the immediate residential location, violent crime causes mental distress when including the surrounding areas, suggesting that this crime type impacts through affecting individuals' daily routines, like travel to work etc. When distinguishing between men and women, we find that women are more responsive to changes in crime rates than men. Our results based on the English Longitudinal Study of Ageing (ELSA), a data set which contains alternative measures of mental health and focuses on a particularly vulnerable group, those above the age of 50 , produces very similar results. 
To further assess the magnitude of our findings, we estimate the effect of the London bombings on the $7^{\text {th }}$ of July 2005 on mental distress. Using a Difference-in-Difference approach, we show that in the months following the attack citizen of London and the other major cities in the UK experienced a significant drop in their self-reported mental health. We find that the reduction in mental wellbeing following a one standard deviation increase in local crime is about one seventh of the fall in mental wellbeing caused by the London Bombings.

Our paper contributes to the literature on estimating intangible costs of crime by focusing on a new and specific aspect. While most of the previous literature has implemented either contingent valuation methods based on stated preferences (Cohen et al. 2004; Atkinson et al. 2005), ${ }^{4}$ or hedonic price models based on revealed preferences (Gibbons, 2004; Linden and Rockoff, 2008), ${ }^{5}$ our study focuses on the detrimental impact of exposure to changes in local crime on mental wellbeing of residents. Our work is also related to a recent paper by Cornaglia, Feldman and Leigh, (2014) on the relationship between mental well-being and crime for Australia. ${ }^{6}$ While Cornaglia, Feldman and Leigh (2014) focus most of their discussion on the difference between being victimized and being exposed to crime (but not victimized), our paper develops an in-depth analysis of the consequences for mental health of exposure to local crime. ${ }^{7}$

Our paper is also related to the literature on neighbourhood effects and mental wellbeing. Several non-experimental studies - almost entirely based on cross-sectional analysis - find significant associations between the mental health of residents and aspects of the neighbourhood

\footnotetext{
${ }^{4}$ See Hausman (2012) for a criticism of the reliability of contingent valuation methods in assessing social costs of changes in environmental quality, and a more positive assessment by Carson (2012).

${ }^{5}$ Gibbons (2004) and Linden and Rockoff (2008) show that house prices fall in response to, respectively, increases in local property crime and the presence of convicted sexual offenders in the area. Similarly, Besley and Mueller (2012) look at the impact of conflict in Northern Ireland (rather than crime) and establish a negative correlation between killings and house prices.

${ }^{6}$ The two papers were part of the project "Crime and mental wellbeing" supported by an ESRC grant (grant number: RES000-22-1979).

${ }^{7}$ With respect to Cornaglia, Feldman and Leigh (2014), we use two alternative datasets, three different measures of mental health and measures of crime rates at two levels of geographical disaggregation. Further, we analyse both timing and heterogeneity of the effects, consider single mental health items and single criminal offences, and benchmark the magnitude of the effects we find against the mental health consequences of a major terrorist attack.
} 
environment. $^{8}$ Based on the Moving to Opportunity (MTO) experiment, a randomized experiment on residential mobility conducted in five US cities in the 1990s, a number of studies have shown that moving away from deprived (high crime) neighbourhoods leads to significant improvements in adult physical and mental health and subjective well-being in the short- (Katz et al. 2001), medium- (Kling et al. 2007) and long-term (Ludwig et al. 2012). ${ }^{9}$ We add to this literature by focusing on the direct link between area crime rates and mental distress of residents who are living in the area, and by providing a precise assessment of the magnitude of these effects. We use longitudinal data and exploit repeated information on both mental wellbeing and area crime to eliminate potential sorting biases. Moreover, we analyse which specific dimensions of mental wellbeing are affected by crime, we distinguish the effects of different types of crime on mental distress, and we assess the heterogeneity in responses across different population groups.

The research we provide in this paper adds to the policy debate on the cost of mental distress to the overall society and on the role played by crime in reducing people's wellbeing. Layard (2005) argues that mental issues represent one of the biggest problems in British society, with serious consequences for the welfare system. He estimates the cost of mental illness at about $2 \%$ of GDP. ${ }^{10}$ Crime is an important aggravating factor: According to the National Institute for Mental Health in England (2005), reducing fear of crime would improve mental health and well-being of Britain's populations. Following an influential independent report on health inequalities produced in the late '90s (Acheson, 1998), the British Department of Health identified decreasing exposure to crime in the neighbourhood as a crucial policy to restrict disparities in health hazard among the British population (Department of Health, 1999), and this is still a key focus of their intervention (Department of Health, 2009). Clearly, the problem is not limited to Britain. The WHO Commission

\footnotetext{
${ }^{8}$ See Mair et al. (2008) and Diez-Roux and Mair (2010) for recent reviews of this literature. In the UK, Propper et al. (2005) find a limited association between neighborhood characteristics and levels (and changes) in mental health of residents.

${ }^{9}$ Oeropolous (2003) exploits quasi-experimental variation in assignment to different public housing projects in Toronto to estimate the impact of neighbourhood characteristics on long-term labour market outcomes of residents, but does not investigate health and mental wellbeing as possible outcomes.

${ }^{10}$ According to the Mental Health Minimum Dataset (MHMDS) in 2008-2009 about 1.2 million people (about 2.3 percent of total population) were in contact with National Health Service (NHS) mental health services in England for serious mental illnesses. Individuals treated for serious mental illness are only a fraction of those suffering from mental distress.
} 
on Social Determinants of Health recognized the level of crime and violence in the area of residence as an important social cause of poor health (CSDH, 2008). Our study contributes to this debate, by providing a precise assessment of the relationship between crime and mental distress.

The paper is structured as follows. Section 2 provides a brief discussion of the underlying mechanisms which link exposure to crime to mental distress, describes the data used for the empirical analysis and reports some descriptive evidence on crime and mental distress in the UK. Our main estimating equation, identification issues and empirical strategy are discussed in section 3. Section 4 reports estimation results and robustness checks. In this section, we also describe how we estimate the impact of the 2005 London bombings, present the estimates and benchmark our previous estimation results on the impact of local crime rates. Finally, the last section contains a brief discussion of our findings and some concluding remarks.

\section{Background, Data and Descriptive Evidence}

\subsection{Local crime and mental distress}

There are at least three channels through which exposure to higher crime in the area of residence may lead to mental distress: an increased level of anxiety and fear of being victimized, a reduced sense of freedom implied by limitations to behaviour (not going out at night, buying a cheaper vehicle than desired, not wearing jewellery, etc.), and the need to plan - and invest in - pre-emptive and deterrent strategies to avoid victimization (e.g. checking carefully windows and back doors when leaving home; hiding valuables; taking longer, but safer, routes to return back home; parking the car only in some areas; etc.). ${ }^{11}$

The extent to which actual crime rates trigger any of these channels depends on how actual crime translates into fears and perceptions about crime. A large literature in the social sciences focuses on

\footnotetext{
${ }^{11}$ A more indirect effect of area crime on residents' mental distress could go through the negative effect crime produces on house prices (Gibbons, 2004). For such a mechanism to be at work, crime shocks should have a persistent effect on expectations of future area crime. We discuss this potential channel in section B2 in the online appendix.
} 
the fear of crime (rather than crime itself; see Hale, 1996), and how perceptions of crime affect mental health (see e.g. Ross and Mirowsky, 2001; Green et al, 2002; Whitley, 2005; Stafford et al., 2007; Jackson and Stafford, 2009). Some authors (see e.g. Ferraro, 1995; Chadee at al. 2007; Smith and Torstensson, 1997) point out that far more people believe they are likely to be a victim of crime than actually end up being victimized. Further, groups who face low objective risks of victimisation are often more concerned about such risks; the elderly are one such example (Mawby, 1992). How actual crime rates translate into individual perceptions and fears, possibly along the channels we outline above, and are then converted into mental distress, is not what we address (and can address) in this paper. Instead, we focus here on estimating the causal effect of local area crime on mental distress of residents. It is this effect - namely, the impact a reduction of crime has on the mental distress of residents, possibly induced by a combination of the different channels discussed above, and probably amplified by individual perceptions - which is an important and relevant policy parameter.

In order to get a sense of the complexity of crime perceptions and of the role played by actual crime in shaping them, consider data for the UK. During the period we analyse in this paper (2002-2008), total recorded crime has decreased by 24 percent: this reduction has been mainly driven by property crime (Figure 1). In spite of this significant fall in crime, the majority of households interviewed in the British Crime Survey believe that crime rates have increased at the national level in recent years. ${ }^{12}$ Indeed, as Figure 1 shows, the fraction of households who believe that crime rates have increased at the national level changed from 65 percent in 2001/02 to about 75 percent in 2008/09. However, respondents seem to have a more accurate assessment about crime rates in their more proximate environment. The share of households that believes crime went up in the neighbourhood

\footnotetext{
${ }^{12}$ The British Crime Survey (BCS) is a systematic victimization survey of a representative sample of people resident in England and Wales. It interviews about 50 thousand adults who are asked about their experiences and perceptions of crime. Victimization surveys usually produce estimates of total crime which are significantly larger than the levels of crime recorded by the police because they manage to capture all the criminal offences (in general, the minor ones) which are not reported to the police. Nevertheless, BCS does not allow to work with geographically detailed and quarterly crime data as we need for the analysis carried out in this paper.
} 
is always smaller and shows a decreasing trend, dropping from 50 percent in 2001/02 to about 35 percent in 2008/09.

Further evidence on the fact that residents are informed about crime rates in the area of residence is reported in Figure A 1 (see appendix) where we have plotted the share of respondents particularly worried about a certain criminal offence (burglary, car crime and violent crime) or a risky behaviour (drug use and dealing, anti-social behaviour) against the actual crime rate of that particular offence in the PFA of residence (period 2002-2008). The positive slope of the fitted lines suggests that concern is higher in regions where crime rates are actually higher. The last negative relationship, instead, shows that respondents are more satisfied with the police intervention in areas where total crime is lower.

\subsection{Data}

Our empirical analysis is based on two large longitudinal surveys, the British Household Survey Panel (BHPS) which contains repeated observations on subjective measures of individual mental health for a representative sample of the British population, and the English Longitudinal Study of Ageing (ELSA), which collects similar information for a sample of individuals above the age of 50 . For both datasets, we match individual records to the crime rate recorded in the months before the interview in their area of residence. Local crime data are provided by the UK Home Office.

\subsubsection{British Household Survey Panel (BHPS)}

The BHPS is an annual survey, which consists of a nationally representative sample of about 5,500 households, containing a total of approximately 10,000 interviewed individuals in the launch year $1991{ }^{13}$ A key advantage of this dataset for our purpose is that it contains rare information about mental health and general wellbeing of interviewees, which is recorded in multiple waves. Under a

\footnotetext{
${ }^{13}$ See https://www.iser.essex.ac.uk/bhps for more information, documentation and data access.
} 
special permission agreement it is possible to obtain the information about the Local Authority of residence of the interviewees at the time of the interview, which allows us to match each respondent to the local crime rates and other area controls in the neighbourhood in the period before the interview. ${ }^{14}$ Given that quarterly crime data are available since 2002 , we use the BHPS waves from 2002 to 2008. Our main estimating sample comprises about 35,000 individual-year observations of residents in urban areas: this corresponds to about 9.4 thousand individuals, whom we observe on average 3.7 times. Almost 40 percent of the respondents are interviewed in all six waves.

The main measure of subjective wellbeing of our empirical analysis is a 12 items version of the General Health Questionnaire (GHQ-12) which is collected in all BHPS waves. The GHQ was developed as a screening instrument for psychiatric illness but is widely used as an indicator of psychological well-being (Goldberg, 1978). It can detect disorders of a temporary nature such as depression and anxiety, but also permanent conditions such as schizophrenia and psychotic depression. GHQ has been used in recent studies by several economists (e.g. Clark, 2003; Gardner \& Oswald, 2007; Metcalfe et al. 2011). The BHPS version of the GHQ has twelve questions, which are combined into a single index by assigning each response between 0 and 3 points and by then summing up across all questions (Likert scoring method). ${ }^{15}$ The highest level of distress, therefore,

\footnotetext{
${ }^{14}$ We match individual information from the BHPS to crime data which is provided quarterly by the Home office starting from the first of January of each year. As interviews in the BHPS are collected throughout (almost) the entire year, it is not meaningful to match individuals interviewed in the first weeks of each quarter with crime rates recorded in the current quarter because most of those criminal events have not taken place at the time of the interview. We thus match interviews collected in the first two months of each quarter with crime rates in the previous quarter, while those collected in the last month of the quarter are matched with crime rates recorded in the current quarter. This implies that people interviewed between the $1^{\text {st }}$ of March and the $31^{\text {st }}$ of May are matched with crime recorded between the $1^{\text {st }}$ of January and the $31^{\text {st }}$ of March, those interviewed between the $1^{\text {st }}$ of June and the $31^{\text {st }}$ of August with crime recorded between the $1^{\text {st }}$ of April and the $30^{\text {th }}$ of June, and so on. Our results are not sensitive to changes by plus or minus 30 days in this matching rule.

${ }^{15}$ Respondents are asked how often (on a four-point category scale) they have recently: lost sleep over worry; felt constantly under strain; felt they could not overcome difficulties; been feeling unhappy and depressed; been losing confidence; been feeling like a worthless person; were playing a useful part in things; felt capable of making decisions; been able to enjoy day-to-day activities; been able to concentrate; been able to face up to problems; and been feeling reasonably happy. See Table A 1 for more details.
} 
scores 36 and the lowest scores $0 .{ }^{16}$ In our empirical analysis, we normalize this index to range between 0 (least distressed) and 1 (most distressed).

Apart from the overall GHQ index, Graetz (1991) identifies three separate and clinically meaningful factors: anxiety and depression, social dysfunction, and loss of confidence. In our empirical analysis we adopt this disaggregation of the GHQ index, and we construct three submeasures of mental wellbeing (GHQ - Anxiety and Depression; GHQ - Social Dysfunction; GHQ Confidence Loss). This disaggregation allows identifying which particular dimensions of respondents' psychology are affected. As for the main GHQ index, we normalize all these indices to range between 0 (least distressed) and 1 (most distressed). Further details on the GHQ questions and on the disaggregation in sub-indices are provided in Appendix A1.1.

In Table 1, we report detailed descriptive statistics on individual characteristics and GHQ measures, all normalised between zero (least distressed) and one (most distressed). The average level of this index is 0.31 , with a median value of 0.28 , an overall standard deviation of 0.15 and a withinindividual standard deviation of 0.1 . However, there is clear heterogeneity with respect to individual characteristics: Mental distress is slightly higher for females, increases (but not monotonically) with age, is lower for the better educated, higher for separated, divorced or widowed individuals, and higher for the unemployed or for people out of the labour force (students, maternity leave, etc.). When GHQ is disaggregated into its three components, the measure of anxiety and depression has a mean of 0.32 with standard deviation of 0.21 (within-individual standard deviation is 0.13 ), while the measure of "social dysfunction" is slightly higher (0.35), with standard deviation of 0.14 (withinindividual standard deviation is 0.1 ). The measure of confidence loss, instead, is substantially lower, with an average of 0.19 and standard deviation equal to 0.23 (within-individual standard deviation is $0.13)$.

\footnotetext{
${ }^{16}$ An alternative scoring method is the "Caseness" bi-modal scoring (0-0-1-1) which gives a total scoring ranging from 0 (least distressed) to 12 (most distressed). Piccinelli et al. (1993) shows that the two methods are basically equivalent. All our empirical results are robust to using the "Caseness" scoring method (as in Metcalfe et al., 2011) rather than the Likert one.
} 


\subsubsection{English Longitudinal Study of Ageing (ELSA)}

The English Longitudinal Study of Ageing (ELSA) is an interdisciplinary biennial survey on health, economic position and quality of life, and representative for people aged 50 and above, and living in private households in England. It comprises about 12,000 respondents. ELSA has now run four waves (2002, 2004, 2006 and 2008). Similarly to the BHPS, information on the Local Authority of residence allows us linking the survey to the crime data.

A rare feature of ELSA is the Psychosocial Health Module (PSH), surveyed in each wave, and asking respondents twelve questions about symptoms of depression. This module is one of the most common screening tests to determine individuals' depression quotient. Besides this depression index, the ELSA contains also a theory-based measure of the quality of life of older adults which consists of 19 questions (CASP-19). Although this latter measure is not exactly conceived as an index of mental wellbeing, it measures perceived general wellbeing of respondents which should reflect also their level of mental distress. Indeed, the type of questions asked to measure GHQ, PSH and CASP-19 are similar in nature (compare Table A 1, Table A 3 and Table A 4). More details on these indices are provided in appendix A1.2. The number of respondents answering all questions of the PSH index is higher than those for the CASP index. Therefore, the sample used to study the latter is slightly larger. After matching respondents with local crime rates, our sample contains about 16,600 (PSH sample) and 13,700 (CASP-19 sample) individual-year observations. Similarly to the GHQ measures, we normalise both the PSH index and the CASP-19 index between 0 (least distressed) and 1 (most distressed).

For the population aged 50 or more, descriptive statistics from the ELSA survey for PSH and CASP-19 indexes are reported in the last rows of Table 1. As for the GHQ indexes, both PSH and CASP-19 have been normalized to vary between zero (highest wellbeing) and one (lower wellbeing). The PSH depression index has a mean value equal to 0.20 , with a standard deviation equal to 0.25 and a 
within-individual standard deviation equal to 0.14 . The mean value of the CASP-19 index, instead, is 0.27 , with a standard deviation (within-individual standard deviation) equal to $0.16(0.06)$.

\subsubsection{Crime Data for England and Wales}

The UK Home office provides quarterly data by Local Authority for various types of criminal offences recorded in England and Wales. ${ }^{17}$ Over the period we analyse (2002-2008) we consistently identify 375 Local Authorities (LAs), 188 of which are urban LAs. ${ }^{18}$ The London area is split in 33 LAs. The average population in one Local Authority is about 145 thousand individuals -110 thousand in rural and 180 thousands in urban LAs. Data can also be aggregated to 43 Police Force Areas (PFA), which reflect the territorial organization of British police forces. ${ }^{19}$

Crime data are available from April 2002 and distinguish between ten categories of crime (burglary, criminal damage, drug offences, fraud and forgery, offences against vehicles, other theft offences, robbery, sexual offences, violence against person and other offences).$^{20}$ The sum of all these items account for the "total crime" recorded in England and Wales (see Table AA 1 in the Appendix for crime definitions). We can further group these types of offences into two broader categories: "violent crime" (robbery, sexual offences, violence against person) and "property crime" (burglary, criminal damage, fraud and forgery, offences against vehicles, other theft offences). ${ }^{21}$ To compute crime rates we divide the total number of offenses in each Local Authority (or Police Force Area) by

\footnotetext{
${ }^{17}$ National police forces separately record criminal offences in Scotland and Northern Ireland. Definitions and recording practices are not currently standardized at the UK level. This generates issues of comparability across countries not only for single types of crime but also for total crime rates. We therefore focus our analysis on England and Wales where data are fully comparable.

${ }^{18}$ According to the British Office for National Statistics definition, urban LAs are defined as LAs where at least 74 percent of the population lives in urban Census Output areas. A Census Output Area is urban if it has a population of over 10 thousand.

${ }^{19}$ PFA are structured such that a number of local authorities lie uniquely within a single police force area.

${ }^{20}$ Police recording practice is governed by the National Crime Recording Standard (NCRS) which was introduced in all police forces in April 2002 in order to make crime recording more consistent. Before that date, data from different years and geographical locations are not directly comparable.

21 "Drug offences" and "other offences" can be considered neither violent nor property crime. They will enter in our empirical analysis only when we look at "total crime" and when we separately analyse each criminal offence.
} 
the resident population in the area (crime rates are expressed in number of offences per ten thousand population).

Table 2 reports descriptive statistics on quarterly crime rates in England and Wales over the period 2002-08. The average quarterly total crime rate was about 226 crimes per 10 thousand population. This rate rises to 280 in urban LAs, with a standard deviation of 97, a within-LA standard deviation of 37 and substantial regional variation (the maximum and the minimum realizations of crime rates being, respectively, 1075 in the London Borough of City of Westminster and 75 in Rochford). Property crime accounts for almost 75 percent of total offenses recorded, violent crime for about 21 percent and the remaining 4 percent corresponds to the residual category of "total other crime". In urban areas, the highest crime rates are recorded for "other theft" (62.5), criminal damage (57.4), violence (50.2), vehicle crime (42.4) and burglary (34.2). When considered together, these five types of criminal offence account for about 88 percent of total recorded crime.

\section{Empirical strategy}

We estimate the following regression equation:

$$
M D_{i r t}=a_{0}+a_{1} C R_{r t}+a_{2} Z_{r t}+a_{3} X_{i t}+T_{t}+L A_{r}+\eta_{i}+u_{i r t}
$$

where the dependent variable $M D_{\text {irt }}$ is a measure of self-reported mental distress of individual $i$ who lives in region $r$ at time t. Our main variable of interest is $C R_{r t}$, which is the $(\log )$ crime rate in area $r$ at time $t$. In our estimation, we will distinguish between different types of crime. Regional time-varying characteristics are given by $Z_{r t}$, while $X_{i t}$ are time-varying individual characteristics. Time and regional (Local Authority, LA) fixed effects are captured, respectively, by $T_{t}$ and $L A$. Finally, $\eta_{i}$ is an individual fixed effect and $\varepsilon_{i t}$ is an idiosyncratic error term. 
The parameter of interest is $\alpha_{1}$, the effect of local crime rates on mental distress. Two problems arise in the estimation of this parameter. ${ }^{22}$ First, sorting of individuals into residential areas may lead to a correlation between area crime rates and mental health that is not causal. Secondly, even if the sorting problem can be addressed, the parameter $\alpha_{1}$ measures the effect of crime and all associated time-varying unobserved neighbourhood characteristics on mental health. While this is a causal parameter (if the sorting problem is solved), it does not measure the pure effect of crime on mental health outcomes.

Our estimation strategy deals with both these problems. Suppose first that individuals do not move across LA's over our sample period. In this case, conditioning on individual fixed effects $\eta_{i}$ corresponds to exploiting only within-area and within-individual variation in crime and eliminates composition effects that are induced through sorting. In addition, this strategy eliminates also area effects that are correlated with both crime rates and mental health status, and that are likely to be constant over the period we consider, such as care institutions, segregation, neighbourhood composition, etc. Moreover, to capture relevant time varying neighbourhood characteristics, we condition on a large set of area characteristics. These include the LA employment rate which controls for the local economic cycle that could affect both crime rates (see Raphael and WinterEbmer, 2001; Gould et al., 2002) and the mental health of residents (Clark and Oswald, 1994). ${ }^{23}$ Further local controls include the share of residents receiving welfare benefits, the share of young adults, the share of immigrants, the number of policemen per capita, and the log population. In addition, we condition on a large set of time-varying individual controls (age, age squared, presence of children in the household, marital status, employment status, education level and log household

\footnotetext{
${ }^{22}$ Local crime realizations are clearly exogenous to individual shocks to mental health. We assume strict exogeneity of the local crime rates, which is plausible, as a shock to individual mental health in any period is unlikely to affect area crime in the same, or in any other, period.

${ }^{23}$ In unreported regressions, we have checked that our results are robust to the inclusion of local unemployment - rather than employment - rates and of labour market controls at the PFA rather than LA level. Results can be provided upon request.
} 
income). Finally, we include a full set of year-quarter dummies to capture any common time effect and potential seasonality in respondents' mental wellbeing.

Some of the respondents in our sample do change area of residence during our observation window. Although movements across LA's are rare (e.g. in the BHPS sample, only about 3.4 percent of respondents change Local Authority of residence every year), we address this problem by considering an individual as a different individual in each area of residence, with a different individual fixed effect, and we only use observations when the respondent has spent two consecutive periods in the same area. This strategy raises two issues. First, it may create acrossindividuals correlation in the error terms. While this may be a concern in a cross-sectional estimation, differencing out all fixed effects should remove this potential source of acrossindividuals correlation. Second, and more importantly, it may introduce some selection bias in our estimation. This bias will materialise only if the decision to move to a new area in period $t$ is affected by the crime rate in the previous residence area in period $t-1$. The sign of the bias depends on the sign of the correlation of the shocks to mental health and to the level of area dislike (which drives moving decisions), and we formally derive it in Appendix A2.

The likelihood that individuals' moves are induced by realizations of crime in the area of residence in the period before the move can be assessed. In all waves, interviewees who live in a different location than in the previous wave are asked to report the main reason of their move. Of these, only 2 percent respond that the main reason was that the previous area was unsafe or unfriendly. ${ }^{24}$ Crime-related moving decisions do thus not seem particularly relevant in our data.

To deal with any remaining concerns, we internalise moves by using larger spatial areas for analysis. We do that by aggregating from Local Authority level to Police Force Areas (PFSs), thus collapsing the 165 urban LAs into the corresponding 41 PFAs. This reduces the share of annual movers in our BHPS

\footnotetext{
${ }^{24}$ Accommodation-related reasons (buying a property, being evicted, moving to smaller/larger house, etc.) account for about 45 percent of the responses, followed by roughly 22 percent for family-related reasons.
} 
sample considerably, from about 3.4 percent to 1.4 percent. ${ }^{25}$ Choosing larger spatial areas as unit of analysis has an added advantages: As individuals may be exposed in their daily routine to different LAs (e.g. when going to work or school, shopping, visiting relative and friends, going out, etc.), crime rates in the immediate residence area alone may be too a narrow spatial definition of crime that causes mental distress. Furthermore, crime perceptions may respond to media coverage that relates to larger areas, better captured by PFA spatial units. We will present our main results using both LA and PFA crime rates. ${ }^{26}$

\section{Results}

We first report estimation results based on BHPS data. Our dependent variables are the overall GHQ and its three sub-components (GHQ-Anxiety, GHQ-Social Dysfunction and GHQ-Confidence). Our main regressor of interest is the log crime rate recorded in the area of residence of the interviewee during the last quarter before the interview. ${ }^{27}$ We also present results from the ELSA sample that covers individuals aged 50 and above.

\subsection{The Effects of Area Crime on Mental Distress}

Table 3 reports our main estimates for the impact of local crime on the overall GHQ measure, which has been normalized between zero (least distressed) and one (most distressed). We have normalised log crime rates by their standard deviation to ease the interpretation of our results. A positive coefficient estimate implies that an increase in crime rates in the area of residence increases the

\footnotetext{
${ }^{25}$ Moreover, our results from the ELSA survey are exempt from this potential bias given that mobility among individuals aged 50 and over is basically zero.

${ }^{26}$ In the Online Appendix B1, we follow an alternative approach to deal with movers across spatial units. We estimate equation (1) using all available observations (rather than only using observations when the respondent has spent two consecutive periods in the same area), and without treating individuals who move as different individuals in each location. We then use an IV type strategy, where we instrument the crime rate to which movers are exposed to with the contemporaneous crime rate in the area where they resided in the first wave of our observation window. All our empirical findings are robust to this alternative estimation strategy.

${ }^{27}$ Estimates with crime rates rather than log crime rates provide very similar results.
} 
level of mental distress of respondents. Standard errors are robust and clustered at the same geographical level as the crime rate variable. In all regressions we control for individual characteristics (age, age squared, a dummy for children in the household, dummies for marital status, for employment status and for education level, and log household income). Moreover, we include a full set of year-quarter dummies to capture any common time effect and potential seasonality in respondents' mental wellbeing. We always condition on the LA employment rate, but in columns 2, 4 and 6 we add further local controls in order to capture additional time-varying local characteristics. ${ }^{28}$ We focus in the Table (and in the reminder of the paper) on estimates obtained for urban areas only, where the upper part and lower part of the table report coefficient estimates of the $(\log )$ crime rate in the LA and PFA of residence, respectively (both measured in the quarter before the interview). ${ }^{29}$

The point estimates reported in the first two columns in the upper part of Table 3 suggest a positive impact in LA log total crime on individual mental distress. The coefficient is significant at the 5 percent level; inclusion of additional LA controls (column 2) does not affect the estimate. When we separate violent (columns 3 and 4) and property crime (columns 5 and 6), the estimated coefficients on both types of crime are positive, but the coefficient on violent crime is substantially smaller and not significantly different from zero. The coefficient on property crime is identical to the one estimated for total crime and statistically significant. Thus, these results suggest that local crime affects mental wellbeing of residents in urban areas, and that the effect is driven mainly by property crime.

How large are these effects? The average value of the GHQ index is 0.31 with an overall standard deviation of 0.15 and a within-individual standard deviation of 0.1 (see Table 1). Thus, and assuming

\footnotetext{
${ }^{28}$ These include: share of residents receiving benefits, share of young adults (individuals aged 15-24 over total adult population), immigrant share, number of policemen per capita and log population size. In unreported regressions, we have also included controls for weather conditions from the UK Met Office (maximum temperature, minimum temperature, days of air frost, total rainfall and total hours of sunshine) in the PFA of residence in the quarter before the interview. This does not affect our estimates.

${ }^{29}$ We do not find a significant relationship between the GHQ index and area crime rates in rural areas, which may be related to the far lower crime rates in these areas (see Table 1), the lower population density, and the therefore lower variation of crime over time.
} 
linearity, an estimated coefficient of 0.008 means that a one standard deviation increase in log total crime rate (or property crime rate) causes a 2.6 percent increase in the GHQ index. It explains about 5.3 percent of its overall standard deviation and 8 percent of its within-individual standard deviation. This is a sizeable impact.

In the lower part of Table 3, we report estimates where crime rates are measured at the PFA level. The estimated coefficients are now larger in magnitude, and more significant. We find that one standard deviation increase in PFA log total crime causes a 0.014 increase in individual mental distress of residents (or 4.5 percent). The coefficient is significant at the 1 percent level even when all the additional LA controls are included in the regression. The coefficient on property crime is of similar magnitude and strongly significant. These regressions also show that violent crime in the area reduces mental wellbeing of residents: The coefficient estimate is about $0.005-0.006$ and significant. One reason for the larger estimates when using PFA's is that the mental distress of people is related to changes in crime in an area larger than the Local Authority of residence. Indeed, as we discuss above, individuals may respond to property and violent crime outside their immediate residence area because they commute to work or they socialize outside their residence LA. Moreover, for relatively rare criminal offences such as violent crime, changes in local crime rates may be hardly observables for local residents who may instead look at larger areas in forming their expectations about victimization risk. In both cases, measuring crime on LA level may simply be too a small measure of neighbourhood crime to pick up harmful effects through mental distress. In fact, it is easy to see that including crime rates on LA level, if what matters for mental distress are crime rates on PFA level, will lead to an underestimate of the effect of crime, while including crime rates at PFA level, if what matters are crime rates at LA level, will not lead to a bias. ${ }^{30}$ Thus, throughout the paper, we will mainly focus on PFA crime rates. ${ }^{31}$

\footnotetext{
30 To see that, consider the equation $C R_{L A}=C R_{P F A}+d_{L A-P F A}$, where $C R_{L A}, C R_{P F A}$ are crime rates on LA and PFA level, and $d_{L A-P F A}$ captures within-PFA variation in crime rates. Thus, $d_{L A-P F A}$ can be thought of as a residual when regressing $C R_{L A}$ on a set of PFA dummies, which makes it immediately clear that it is not correlated with $R_{P F A}$. In this special case, erroneously using $C R_{P F A}$ as regressor while $C R_{L A}$ should be used will lead to unbiased estimates, as the
} 
To gain further insight on the magnitude of these effects we compare the estimated effects with those of the local employment rate on residents' mental well-being. The coefficient estimates in the last row show that changes in the local employment rate are significantly, and negatively, associated with changes in mental distress of residents. The estimated coefficients suggest that a 10 percentage points increase in local employment rate improves residents' mental health by about 8 percent of its within-individual standard deviation. Thus, a one standard deviation reduction in the LA (PFA) log total crime rate roughly the same amount as a $10(20)$ percentage points. Given that the standard deviation of the local employment rate is just 5 percentage points, the impact of a one standard deviation decrease in the crime rate on mental health is about twice to four times as large as a one standard deviation increase in the local employment rate.

Further comparisons can be made by looking at the estimated coefficients on individual controls (reported in Table AA 2 in the appendix). Consistently with the literature on the impact of major individual life events (getting married, divorcing, having a baby, being laid off, etc.) on individual happiness (see, among others: Clark et al., 2008; Frijters et al., 2011; Clark and Georgellis, 2013), we find strong and negative short-run effects on mental wellbeing of losing a partner, becoming unemployed or suffering a disabling injury. According to our estimates, the effect of a one standard deviation increase in the local crime rate on mental distress is about one seventh to one fifth of the short-run effect of becoming unemployed. This is quite substantial, in particular when considering that the estimates for local crime rates are the average effects for all residents, while the effects of changes in personal circumstances relate only to those who are affected.

We report some robustness checks in Table AA 3, where we include, alternatively, a linear trend at the PFA level (columns 2) and at the LA level (columns 3). In addition, we test whether initial conditions in mental health, crime rates and other controls matter for the empirical relation we

measurement error $d_{L A-P F A}$ is not correlated with the included regressor $C R_{P F A}$; however, using $C R_{L A}$ as a regressor when $C R_{P F A}$ is the correct measure of area crime will lead to a downward bias in estimates. See also Wooldridge 2002, $\mathrm{p}$. 74.

${ }^{31}$ We have also estimated the same models using the Within Group estimator, obtaining very similar estimates. Results can be provided upon request. 
uncover. For each LA in our sample, we have computed initial average crime rates (total, property and violent) in year 2002. Moreover, for the period 1999-2001, we compute the average GHQ score, averages of all BHPS individual controls and averages of all LA controls used in the main specification. In column 4 to 7 of Table AA 3, we progressively include these baseline LA controls interacted with year dummies in our estimating equation. In columns 8 and 9, we alternatively add to these controls a PFA and a LA linear trend. The estimates are remarkably similar across all these specifications.

\subsection{Decomposing Mental Distress Measures}

We now address the question whether the overall impact of local crime on mental distress established above is related to increased levels of anxiety and depression, or loss of self-confidence or social functionality. To do that, we use the disaggregated indicators GHQ-Anxiety and Depression, GHQ-Social Dysfunction and GHQ-Confidence Loss (see Appendix A1.1). In Table 4, we report estimates for the specifications that include all controls.

If anything, one would expect exposure to crime to induce stress and anxiety, and to reduce the capability of enjoying daily activities. This direct effect could then reduce self-confidence and social interaction. Indeed, Stafford et al. (2007) find that individuals with pronounced fear of crime are twice as likely to suffer from depression as individuals who are less concerned about crime. In line with this, our estimates show a strong adverse effect of local crime on the level of anxiety and depression of residents. The other two dimensions - social dysfunction and confidence loss- are also affected but to a lesser extent. As before, the effects seem to be mainly driven by property crime, and estimates are larger when aggregating data up on PFA level. At that aggregation level, violent 
crime has also an effect on anxiety and depression as well as on confidence loss, although smaller in magnitude. $^{32}$

\subsection{Different crime types}

Our data distinguishes between ten different categories of crime. ${ }^{33}$ This allows us to investigate more specifically which type of crime causes mental distress to residents. For the overall GHQ and its three sub-components, and using the PFA aggregation, we report estimation results in Table AA 5. We find strong effects on mental health of almost all property crime types, such as burglary, criminal damage, vehicle crime and "other theft", which all significantly increase the level of mental distress of residents in the area. These types of crime account together for about 70 percent of total recorded crime in the UK (see Table 2). ${ }^{34}$ Moreover, we find a clear detrimental effect of violence on the mental health of people. Violence is by far the most frequent crime type in the category "violent crime", accounting for more than 86 percent of the total (Table 2). The non-significant effects of robbery and sexual crime need to be interpreted bearing in mind that these are extremely rare events. Indeed, these two criminal offences together account for less than 3 percent of total recorded crime: on average, only $3(5)$ individuals per 10 thousand population are victims of sexual offences (robberies) in each quarter.

When the GHQ index is decomposed into its three sub-factors, we find - as before - the largest effects on the anxiety and depression index.

\footnotetext{
${ }^{32}$ We have also broken down the GHQ index in its 12 components. Eight out of twelve of them are significantly affected by local crime rates at the PFA level, with a detrimental impact of crime on the ability to concentrate, the perception of playing a useful role in life, the feeling of being constantly under strain, the ability to overcome difficulties, the enjoyment of daily activities, the feeling of being depressed, the sense of worthiness and the level of happiness (see Table AA 4).

${ }^{33}$ These are: burglary, criminal damage, drug offences, fraud and forgery, offences against vehicles, other theft offences, robbery, sexual offences, violence against the person and other offences (see Table AA 1 for crime definitions).

34 "Fraud and forgery", although having a positive coefficient, is non-significant. One reason could be that this type of crime is recorded where the victims reside, but has no clear connection with the local environment (like e.g. credit card forgery).
} 


\subsection{Heterogeneous effects of crime}

Different individuals may respond to crime in different ways. Indeed, both actual crime risk and fear of crime are socially stratified, with some social groups being more affected than others. Some research suggests that women and the elderly are more concerned about crime (Lagrange and Ferraro, 1989), possibly because they feel particularly vulnerable (Smith and Torstensson, 1997). The more educated may also be more aware of changes in local crime rates and, therefore, react more. On the other hand, insofar as their higher level of education reflects their income group, they may be less exposed to criminal hazard. The presence of children in the household may be an additional reason of added mental distress through area crime for parents and older relatives. To investigate whether responses are heterogeneous along these dimensions, we interact area crime rates with observed individuals characteristics and report results in Table 5.

We find a clear gender dimension in the impact of exposure to crime on mental health. ${ }^{35}$ While a one standard deviation increase in log total crime causes an increase of 0.008 points in the overall GHQ index for men, the effect on women is more than twice as large. Breaking crime down into violent crime and property crime shows that the effects of property crime are similar to those of total crime, with an effect on female residents which is exactly twice as large as those on males. Moreover, the effects of violent crime discussed earlier are driven only by females, with a one standard deviation increase in the violent crime rate increasing women's overall GHQ index by about 0.008 points.

We have also investigated whether the effect of crime is more/less pronounced for those under 30, over 65, with a higher education, or living in household with children. As the estimates in Table 5 show, these interaction terms are mostly non-significant, while the gender heterogeneity is robust to their inclusion.

\footnotetext{
${ }^{35}$ This finding is consistent, for instance, with Frijters et al. (2011) who demonstrate that life satisfaction of Australian women is more strongly affected by (property) crime than that of men.
} 


\subsection{The Timing of the Effect of Crime on Mental Distress}

Our indices of mental health are subjective and self-reported measures that refer to interviewees' assessment as to how they felt around the time of the interview along different dimension of mental wellbeing. ${ }^{36}$ So far, we have shown that exposure to crime shocks in the quarter before the interview leads to lower mental wellbeing of residents. One important question is whether the effect of crime on mental distress fades away quickly, or whether it causes more persistent mental distress.

We now investigate whether previous lags of local crime rates produce a significant effect on current mental wellbeing. In addition, we test the robustness of our results to a straightforward - but powerful - falsification exercise, by regressing current mental health status on future crime.

Table 6 reports estimation results for total crime at the PFA level. Given that crime data start in April 2002 (see section 2.2), when working with crime lags we gradually lose observations of individuals interviewed in 2002-2003. Thus, to allow meaningful comparison of coefficients across different regressions, we restrict the sample to all those who have non-missing values for the third lag of the quarterly crime rate. This implies a 20 percent reduction with respect to our main estimation sample. In the table, we define as "quarter $Q$ " the last quarter before the interview (i.e. our main measure of crime throughout the paper), while lags (leads) are defined as, respectively, $Q-1, Q-2, \ldots$ $(Q+1, Q+2, \ldots)$.

The first column reports an estimate of the effect of local crime recorded in the last quarter before the interview on mental wellbeing of residents. The coefficient is almost identical to our baseline estimate reported in Table 3. We then include lags and leads of crime, each one at a time (columns 2-6) and all of them together (column 7). There seems to be some persistence of the effect: the first and second lags of crime (columns 2-3) have a sizeable and significant effect on current mental wellbeing, but the effect disappears with the third lag (column 4). Instead, future realizations of crime do not explain current mental health (columns 5-6). In column 7, we include current crime, as

\footnotetext{
${ }^{36}$ All twelve GHQ questions use the following wording: “Have you recently....felt/been/etc.?” (see Table A 1).
} 
well as all leads and lags. The estimated coefficients for quarter $Q$ is identical in magnitude (although the standard error is slightly larger), remaining unaffected by the inclusion of the other crime controls. All the other coefficients, instead, are smaller, and far from significant.

In our dataset, adjacent changes in quarterly crime rates are strongly correlated (correlation is about 0.7), suggesting the existence of local crime cycles that last more than one quarter, which may suggest that it is meaningful to consider more than one quarter as a time window to crime exposure. We have done this in the last three columns of the table, where we have repeated the same analysis using six-month intervals (average crime rate over two quarters) rather than single quarters (columns 8-10). ${ }^{37}$ The pattern we observe does not change: crime rate in the six months before the interview (column 8) produces a sizeable and significant detrimental effect on mental health, while crime rate 6-12 months before the interview does not seem to have any effect (column 9). Taken together, these findings suggest that fluctuations in local crime produce a temporary effect on subjective mental wellbeing of residents.

We find further evidence of the temporariness of this effect by investigating the impact of local crime on more permanent measures of mental health and on the overall health of the interviewees. The BHPS questionnaire includes questions on whether respondents suffer from depression or anxiety among their main health problems, whether they are addicted to alcohol or drugs, and whether they visited a psychotherapist during the last year. The BHPS also records both a subjective assessment of health status and more objective measures such as whether the respondent went to see her GP or she was in-patient/out-patient at the hospital in the last year. We have run regressions using our main specification, but replacing GHQ indices with each of these outcomes as dependent variable. We find no significant relationship between any of these outcomes and crime rates

\footnotetext{
${ }^{37}$ When six-month periods are considered rather than quarters, the correlation between contiguous changes in crime rate drops from 0.7 to 0.3 .
} 
recorded in the last three, six or twelve months before the interview. Estimation results can be provided upon request.

All this evidence points at exposure to crime being a stressful but temporary event, which creates mental distress in the short run, but has no immediate repercussions on more permanent mental conditions, subjective health, or attendance of health services. The temporariness of the effect we identify is fully consistent with the existing literature on wellbeing which shows that individuals tend to adapt fairly quickly to major individual life events such as getting married, divorcing, having a baby, being laid off, etc., see for instance work by Clark and Georgellis (2013), Clark et al. (2008) and Frijters et al. (2011).

However, temporariness of the effects does not imply that exposure to crime in the area of residence can be disregarded. Rather, although area crime may not have persistent effects on mental distress, it is a repeated shock: different from other personal lifetime events that occur rarely, residents are permanently exposed to temporary crime shocks. Even if individuals fully recover after each shock, this implies that in any given period there will be a sizeable fraction of the population - those living in areas hit by negative crime shocks - who is more mentally distressed than in the absence of such shocks. This may have important consequences for their behavior, relationships and productivity. ${ }^{38}$

\subsection{Results using the English Longitudinal Study of Ageing}

We now turn to the data from the English Longitudinal Study of Ageing (ELSA), focussing on people aged 50 and above. ELSA contains two alternative measures of mental wellbeing: a depression index (PSH), and a measure of quality of life of older adults (CASP-19). To check the robustness of our

\footnotetext{
${ }^{38}$ Although our setting does not allow us to identify the cumulative impact of having being exposed to repeated temporary crime shocks, the evidence from the Moving to Opportunity (MTO) experiment, shows that moving away from deprived areas - i.e. areas where individuals are more exposed to crime shocks - leads to significant improvements in both subjective and objective well-being (Katz et al. 2001; Kling et al. 2007; Ludwig et al. 2012).
} 
results, we replicate our previous analysis using this alternative dataset and measures of mental wellbeing. ${ }^{39}$

Table 7 reports FD estimates of regressing the PSH and the CASP-19 indices on local crime in the LA (upper part of the table) or PFA (lower part of the table) of residence. In spite of the differences in data, sample and measure of mental distress, our empirical findings are fully consistent with our previous results. Local crime increases mental distress of residents, with property crime seemingly playing a larger role. In particular, the depression index PSH is significantly higher for individuals exposed to higher crime: a one standard deviation increase in total crime in the LA of residence increases the PSH index by 0.024 points. This implies a 12 percent increase with respect to its mean value (0.2) and would explain up to 17 percent of its within-individual standard deviation (0.14). Similarly, a one standard deviation increase in crime raises the CASP index by 0.008 points, which corresponds to a 3 percent increase with respect to its mean value (0.27) and to 13 percent of its within-individual standard deviation (0.06). Very similar coefficients are found for PFA crime rates.

In unreported regressions, we have looked at which specific crime types produce the strongest negative impact on resident mental wellbeing. Consistently with the evidence from the BHPS data discussed above (section 4.3), we find the largest and more significant coefficients for burglary, vehicle crime and violence. ${ }^{40}$

\subsection{Assessing the Magnitude of Crime Effects}

How large is the effect of being exposed to exogenous changes in local crime rates on individuals' mental health? We gave a first answer to this question by comparing our estimates with the impact of the local employment rate (see section 4.1), and the impact of changes in personal circumstances, such as becoming unemployed. In this section we investigate this aspect further, by contrasting the effects of changes in local crime rates to the effect to a major violent terrorist attack which had a

\footnotetext{
${ }^{39}$ Given the age profile of the respondents, residential mobility is almost non-existent in the ELSA dataset: in each period, between 0 and 0.3 percent of interviewees have changed LA of residence with respect to the previous wave.

${ }^{40}$ Results can be provided upon request.
} 
dramatic impact on the UK: the 7 July 2005 London bombings. This was a series of coordinated suicide attacks on London's public transport system during the morning rush hours. The different explosions killed 52 people and injured about 700 . The attacks were completely unexpected and represented the first terrorist act of Muslim extremists in the UK. The impact of this event on British residents was quite dramatic. ${ }^{41}$

The BHPS data allow us to investigate the impact the $7 / 7$ attack had on UK residents' self-reported mental health, as interviews are carried out throughout the entire year, so that, in 2005 , some individuals have been interviewed before, and some after that event. Unfortunately, the immediate period before and after the terrorist attack is not covered by the data, as interviews routinely stop in May and start again in September (see Table AA 6). We make use of a Difference in Difference (DID) approach to identify the effect of interest. A similar identification strategy has been implemented with BHPS data by Metcalfe et al. (2011) to estimate the effect of the September 11 attacks on the subjective wellbeing of the British population.

We identify the causal impact of the London Bombing on British citizens' mental health by comparing those interviewed in the months preceding the bombing with those interviewed in the months following the event. Our identification strategy assumes that the timing of the interview with respect to the date of the London bombings - is random. A first concern arises from the possibility that interviewers could manipulate the date of their interview in response to the London bombings. This seems unlikely as the terrorist attack - by definition - was unexpected and there is no reason to expect it to have affected the scheduled timings of BHPS interviews. ${ }^{42}$ In any case, if individuals more negatively affected by the $7 / 7$ attack refused to answer the BHPS questionnaire in the months after the event, we would estimate a lower bound of the overall effect. A second, more relevant, problem with this identification strategy is seasonality in responses: mental distress may

\footnotetext{
${ }^{41}$ Rubin et al. (2005) and Rubin et al. (2007) illustrate the impact on stress and perceived threat as well as travel behaviour among Londoners in the aftermath of the event. Similar negative effects on mental wellbeing have been observed among the American population after the $9 / 11$ attacks (Stein et al., 2004).

42 In addition, BHPS does not carry out interviews during the summer (Table AA 6). Thus, the possible disruptions in the interview schedule by the terrorist attack in its immediate aftermath are not a concern here.
} 
differ in different months during the year. If autumn and winter months have a detrimental effect on mental wellbeing, then at least part of the increase in mental distress after the $7 / 7$ bombings could be driven by this seasonal effect. We remove these effects by combining the before-after analysis with a DID approach, comparing the difference in 2005 (before and after July) with that measured in the year before (2004). ${ }^{43}$ We thus estimate the following regression:

$$
M D_{i t}=\beta_{0}+\beta_{1} \text { AfterJuly }_{i}+\beta_{2}{\text { year } 2005_{i}}+\beta_{3}\left(\text { AfterJuly }^{*} \text { year } 2005\right)_{i}+v_{i t}
$$

Here $M D_{i t}$ is the level of mental distress of individual $i$ at time $t$. We identify the treated group with a dummy variable Year2005 which is equal to one if the interview was carried out in 2005 (rather than in 2004). The "treatment" dummy AfterJuly, instead, is equal to one if the interview took place after July. The coefficient of interest is $\beta_{3}$, which is equal to one for those individuals interviewed between September and December in 2005 (that is, in the aftermath of the bombing). As before, we use as dependent variable the mental wellbeing measured by GHQ (or by its sub-components: anxiety, social dysfunction and confidence). Alternatively, we use the residuals from regressing GHQ measures on individual characteristics, Local Authority fixed effects and year and month dummies. ${ }^{44}$ Our design should randomise individuals across all these characteristics. Indeed, using either measure leads to basically the same results, which is what one would expect if respondents' characteristics are orthogonal with respect to the date of the interview. In all regressions, we cluster the standard errors by local authority of residence to allow for any possible correlation in the mental distress shocks of individuals living in the same area.

We report results of our DID estimates in Table 8 . We start by looking at all LAs. We then progressively restrict the sample to the main 20 cities (in terms of population), the main 5 cities and,

\footnotetext{
${ }^{43}$ Including year 2003 does not substantially alter our findings. We do not use years after 2005, because permanent changes - such as the permanently higher levels of alert described in the previous section - may confound the effects.

${ }^{44}$ As in our previous analysis, individual controls are: gender, age, age squared, a dummy for children in the household, dummies for marital status, employment status, categorical variables for education level, and log household income.
} 
finally, Greater London (which contains 33 Local Authorities). ${ }^{45}$ In each case, our dependent variable is first the GHQ index and then the residual GHQ. In the third column of each sample we restrict the observations of those interviewed "after July" only to the interviews collected in September (rather than using the period September-December).$^{46}$ In the last three columns, instead, we look at the three (residual) GHQ subcategories (still using only individuals interviewed in September in the "after July" group).

In all regressions, we find a positive coefficient on $\beta_{3}$, suggesting that, in the aftermath of the London bombings, individuals reported a higher level of mental distress. The coefficient increases in size and becomes strongly significant when we restrict the sample to the main 20 cities, the main 5 cities, or just London. Thus, the impact of the London bombings is larger on urban residents who are more exposed to the risk of a terrorist attack. Results for GHQ or residual GHQ are almost identical, as are results we obtain when we drop individuals interviewed between October and December. Finally, columns 3-6 show that most of the impact seems to be on anxiety and depression. This is similar to the results we find for overall crime. There are also sizeable effects on Social Dysfunction, but no significant effect on Confidence Loss - again, similar to what we find for local area crime.

When we focus on the main 5 cities and on Greater London, in the months immediately following the bombing, the self-reported mental distress increased by roughly 0.1 points, implying that the GHQ index increased by more than 30 percent with respect to its mean value (which is about 0.3 ); this accounts for about 65 percent of its standard deviation (and for 100 percent of its within standard deviation).

How large are the effects of crime changes in the area of residence in comparison to those we find for the London bombing? We report above that a one standard deviation increase in log crime rates implies an increase in the GHQ index of 0.014 points. This implies that a one standard deviation

\footnotetext{
${ }^{45}$ The main 20 cities are: Birmingham, Bradford, Bristol, Cardiff, Coventry, Derby, Kingston-upon-Hull, Leeds, Leicester, Liverpool, London, Manchester, Newcastle upon Tyne, Nottingham, Plymouth, Sheffield, Southampton, Stoke-on-Trent, Swansea, and Wolverhampton. The main 5 cities are: Birmingham, Bradford, Leeds, London and Sheffield.

${ }^{46}$ The limited simple size of those interviewed in the first six month of the year, does not allow us to restrict the control group only to individuals interviewed in May (see Table AA 6).
} 
change in the local crime rate on residents' mental wellbeing is about $1 / 7$ of that induced by the 2005 London bombing in the months immediately following the terrorist attack. This is sizeable, given the dramatic effect the London bombing had on the British population. Moreover, while the London bombing was a one-off incident, changes in local crime happen on a continuous scale.

\section{Conclusions}

In this paper, we analyse the indirect and intangible costs of crime, through inflicting mental distress, depression and anxiety, on individuals who live or work in the vicinity where crime takes place. We exploit detailed panel data on mental wellbeing from two longitudinal surveys and we find that local crime rates have a significant, negative, and substantial effect on mental well-being in urban areas. While most of this effect works through property crime, violent crime turns out to be important when we increase the area within which crime is recorded. This suggests that - while property crime concerns individuals mostly when committed in their immediate neighbourhood - violent crime is also relevant for the mental distress of citizens when it takes place in a larger spatial area around their habitation. We benchmark our results with the impact on mental health of British citizens of local unemployment rates, and the London bombings in July 2005. We show that the effect of a one standard deviation increase in the crime rate on mental health is about twice to four times as large as a one standard deviation increase in the local employment rate; and about one seventh of the impact of the London bombing - which was a dramatic event. We conclude that the effects of local crime on mental distress of citizens are large, with possibly significant economic costs. Thus, crime reduction and crime prevention may have benefits far beyond those typically suggested. 


\section{References}

Acheson D. (chaired by) (1998) "Independent Inquiry into Inequalities in Health", http://www.archive.official-documents.co.uk/document/doh/ih/ih.htm

Atkinson G., Healey A. and Mourato S. (2005) "Valuing the Costs of Violent Crime: A Stated Preference Approach", Oxford Economic Papers 57: 559-585

Becker G. and Rubinstein Y. (2011) "Fear and the Response to Terrorism: An Economic Analysis", CEP Discussion Paper No 1079.

Besley T. and Mueller H. (2012) "Estimating the Peace Dividend: The Impact of Violence on House Prices in Northern Ireland", American Economic Review, 102(2): 810-33

Braakman N. (2013) "How do Individuals Deal with Victimization and Victimization Risk? Longitudinal Evidence from Mexico", Journal of Economic Behavior and Organization, 84(1), pp. 335-344.

Carson R.T. (2012) "Contingent Valuation: A Practical Alternative When Prices Aren't Available", Journal of Economic Perspectives, 26(4): 27-42.

Chadee D., Austen L. and Ditton J. (2007) “The Relationship Between Likelihood and Fear of Criminal Victimization: Evaluating Risk Sensitivity as a Mediating Concept", British Journal of Criminology, 47 (1): 133-153

Clark A.E. and Oswald A.J. (1994) "Unhappiness and Unemployment", Economic Journal, 104: 648659

Clark A.E. (2003) "Unemployment as a Social Norm: Psychological Evidence from Panel Data", Journal of Labor Economics, University of Chicago Press, vol. 21(2): 289-322

Clark, A.E., Diener, E., Georgellis, Y. and Lucas, R. (2008). "Lags and Leads in Life Satisfaction: A Test of the Baseline Hypothesis", Economic Journal, 118: F222-F243

Clark, A. and Georgellis, Y. (2013) "Back to baseline in Britain: Adaptation in the British Household Panel Survey", Economica, (in Press)

Cohen M.A., Rust R.T., Steen S. and Tidd S.T. (2004) "Willingness to Pay for Crime Control Programs", Criminology 42 (1): 89-109.

Cornaglia F., Feldman N.E. and Leigh A. (2014) "Crime and Mental Wellbeing", Journal of Human Resources, 49(1): 110-140

CSDH (2008) "Closing the Gap in a Generation: Health Equity Through Action on the Social Determinants of Health", WHO - Commission on Social Determinants of Health

Department of Health (1999) "Reducing Health Inequalities: an Action Report", London, Department of Health 
Department of Health (2009) "Tackling Health Inequalities: 10 Years On", London, Department of Health

Diez-Roux A.V. and Mair C. (2010) "Neighbourhoods and health", Annals of the New York Academy of the Sciences, 1186: 125-45.

Dolan P., Loomes G., Peasgood T. and Tsuchiya A. (2005) "Estimating the Intangible Victim Cost of Violent Crime", British Journal of Criminology, 45(6): 958-76

Dubourg R., Hamed J. and Thorns J. (2005) "The Economic and Social Costs of Crime Against Individuals and Households 2003/04", Home Office On-Line Report 30/05

Ferraro, K. (1995) 'Fear of Crime: Interpreting Victimisation Risk' Albany: SUNY Press.

Frijters P., Johnston D.W. and Shields M.A. (2011) "Life Satisfaction Dynamics with Quarterly Life Event Data," Scandinavian Journal of Economics, Wiley Blackwell, vol. 113(1): 190-211

Gardner J. and Oswald A.J. (2007) "Money and Mental Wellbeing: a Longitudinal Study of MediumSized Lottery Wins", Journal of Health Economics, Elsevier, vol. 26(1): 49-60

Gibbons S. (2004) "The Costs of Urban Property Crime", The Economic Journal, 114 (499): F441-F463 Goldberg, D. (1978) "Manual of the General Health Questionnaire", Windsor: National Foundation Gould E.D., Weinberg B.A. and Mustard D.B. (2002) "Crime Rates and Local Labor Market Opportunities in the United States: 1979-1997", The Review of Economics and Statistics, Vol. 84(1): 45-61

Graetz B (1991) "Multidimensional Properties of the General Health Questionnaire", Social Psychiatry and Psychiatric Epidemiology, 26: 132-138

Green, G., Gilbertson J.M., Grimsley M.F.J. (2002) 'Fear of Crime and Health in Residential Tower Blocks', European Journal of Public Health, 12: 10-15

Hale, C. (1996) "Fear of Crime: a Review of the Literature", International Review of Victimology, 4: $79-150$

Hamermesh, D.S. (1999) "Crime and the Timing of Work", Journal of Urban Economics 45: 311-30.

Harrendorf S., Heiskanen M. and Malby S. (edited by) (2010) "International Statistics on Crime and Justice", HEUNI-UNDOC

Hausman J. (2012) "Contingent Valuation: From Dubious to Hopeless", Journal of Economic Perspectives, 26(4): 43-56

Hyde M., Wiggins R.D., Higgs P. and Blane D.B. (2003) “A Measure of Quality of Life in Early Old Age: the Theory, Development and Properties of a Needs Satisfaction Model (CASP-19)", Aging \& Mental Health, 7(3):186-194.

Jackson J. and Stafford M. (2009) "Public Health and Fear of Crime: A Prospective Cohort Study", British Journal of Criminology, 49: 832-847. 
Janke K., Propper C. and Shields M.A. (2013) "Does Violent Crime Deter Physical Activity?," IZA Discussion Papers 7545, Institute for the Study of Labor (IZA).

Katz L.F., Kling J.R. and Liebman J.B. (2001) "Moving To Opportunity In Boston: Early Results Of A Randomized Mobility Experiment", The Quarterly Journal of Economics, MIT Press, 116(2): 607654

Kling J.R., Liebman J.B. and Katz L.F. (2007) "Experimental Analysis of Neighbourhood Effects," Econometrica, Econometric Society, 75(1): 83-119

Lagrange R.L. and Ferraro K.F. (1989) “Assessing Age and Gender Differences in Perceived Risk and Fear of Crime", Criminology, 27: 697-720.

Layard R. (2005) “Mental Health: Britain's Biggest Social Problem?”, presented at the No.10 Strategy Unit Seminar on Mental Health, 20th January 2005

Linden L. and Rockoff J.E. (2008) "Estimates of the Impact of Crime Risk on Property Values from Megan Law", American Economic Review, American Economic Association, 98(3): 1103-27

Ludwig J., Duncan G.J., Gennetian L.A., Katz L.F., Kessler R.C., Kling J.R. and Sanbonmatsu L. (2012) "Neighborhood Effects on the Long-Term Well-Being of Low-Income Adults", Science 21 September 2012: 337 (6101): 1505-1510

Mair C., Diez Roux A.V. and Galea S. (2008) "Are Neighbourhood Characteristics Associated with Depressive Symptoms? A Review of Evidence", Journal of Epidemiology and Community Health, 62: $940-946$

Mawby, R. (1992) Crime and the elderly: a review of British and American research, Current Psychological Reviews, vol 2(3), pp. 301-310

Metcalfe R., Powdthavee N. and Dolan P. (2011) "Destruction and Distress: Using a Quasi-Experiment to Show the Effects of the September 11 Attacks on Mental Well-Being in the United Kingdom," Economic Journal, Royal Economic Society, 121(550): F81-F103

National Institute for Mental Health in England (2005) "Making it possible: Improving mental health and well-being in England", National Institute for Mental Health in England

Oreopoulos P. (2003) "The Long-Run Consequences of Living in a Poor Neighborhood", The Quarterly Journal of Economics, 118(4): 1533-1575

Piccinelli M., Bisoffi G., Bon M.G., Cunico L. and Tansella M. (1993) "Validity and Test-Retest Reliability of the Italian Version of the 12-item General Health Questionnaire in General Practice: a Comparison Between Three Scoring Methods", Comprehensive Psychiatry, 34(3): 198-205

Propper C., Jones K., Bolster A., Burgess S., Johnston R. and Sarker R. (2005), "Local Neighbourhood and Mental Health: Evidence from the UK", Social Science \& Medicine, 61(10): 2065-2083 
Radloff L.S. (1977) "The CES-D Scale: A Self-Report Depression Scale for Research in the General Population", Applied Psychological Measurement, 1: 385-401

Raphael S. and Winter-Ebmer R. (2001) "Identifying the Effect of Unemploymenton Crime", Journal of Law and Economics, 44(1): 259-283

Ross, C.E. and Mirowsky, J. (2001) "Neighborhood disadvantage, disorder, and health", Journal of Health and Social Behaviour, 42: 258-276

Rubin, G.J., Brewin, C.R., Greenberg, N., Simpson, J. and Wessely, S. (2005) "Psychological and Behavioural Reactions to the Bombings in London on 7 July 2005: Cross Sectional Survey of a Representative Sample of Londoners", British Medical Journal, 331: 606-611

Rubin, G.J., Brewin, C.R., Greenberg, N., Simpson, J. and Wessely, S. (2007) “Enduring Consequences of Terrorism: 7-Month Follow-up Survey of Reactions to the Bombings in London on 7 July 2005", The British Journal of Psychiatry, 190: 350-356

Sa Filipa (2011) Immigration and House Prices in the UK, IZA, Discussion Paper No. 5893

Smith W.R. and Torstensson M. (1997) "Gender Differences in Risk Perception and Neutralizing Fear of Crime: Toward Resolving the Paradoxes", British Journal of Criminology, 37(4): 608-634

Soares R.R. (2010) "Welfare Costs of Crime and Common Violence: A Critical Review," Textos para discussãfo 581, Department of Economics PUC-Rio

Stafford, M., Chandola, T. and Marmot, M. (2007) "Association Between Fear of Crime and Mental Health and Physical Functioning", American Journal of Public Health, 97(11): 2076-2081

Stein B.D., Elliott M.N., Jaycox L.H., Collins R.L., Berry S.H., Klein D.J., Schuster M.A. (2004) “A National Longitudinal Study of the Psychological Consequences of the September 11, 2001 Terrorist Attacks: Reactions, Impairment, and Help-Seeking", Psychiatry: Interpersonal and Biological Processes, 67(2): 105-117

Whitley, R. and Prince, M. (2005) "Fear of crime, mobility and mental health in inner-city London, UK", Social Science and Medicine, 61: 1678-1688.

Wooldridge, J. (2002) "Econometric Analysis of Cross Section and Panel Data”, MIT Press 


\section{Figures}

Figure 1 - Trends in crime and in perceptions about crime: 2001-2009

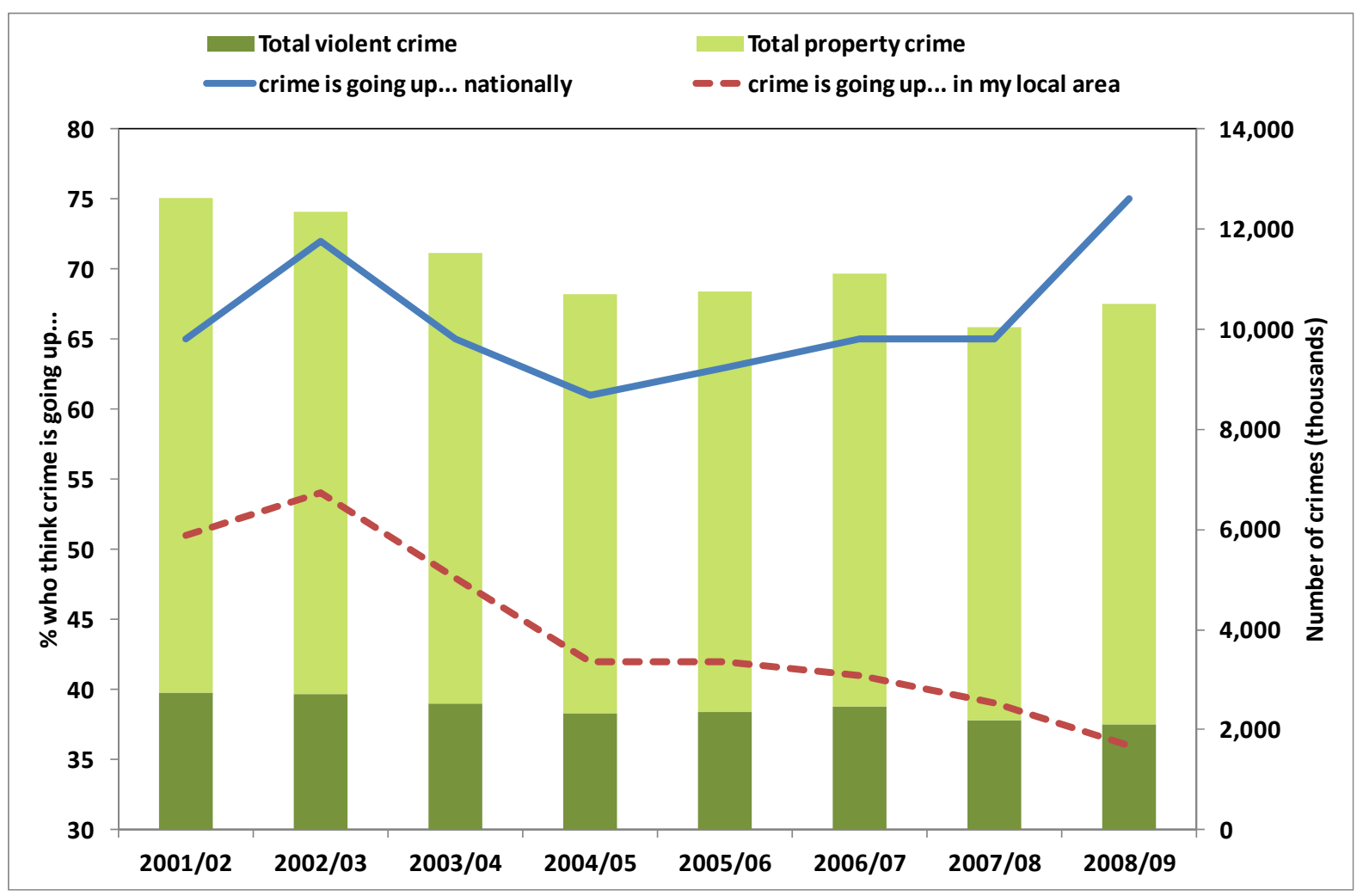

Note. Authors' calculations from British Crime Survey (BCS); waves 2001/02 - 2008/09 
Tables

Table 1 - Mental health: descriptive statistics (BHPS and ELSA)

\begin{tabular}{|c|c|c|c|c|c|c|c|}
\hline & & mean & median & std dev & $\begin{array}{c}\text { within std } \\
\text { dev }\end{array}$ & $\begin{array}{c}\text { observations } \\
\text { (individual- } \\
\text { year) }\end{array}$ & $\begin{array}{c}\% \text { of total } \\
\text { observati } \\
\text { ons }\end{array}$ \\
\hline \multicolumn{8}{|c|}{ BHPS } \\
\hline \multicolumn{8}{|c|}{ GHQ index } \\
\hline \multirow{4}{*}{\multicolumn{2}{|c|}{$\begin{array}{c}\text { GHQ - Overall } \\
\text { GHQ - Anxiety and Depression } \\
\text { GHQ - Social Dysfunction } \\
\text { GHQ - Confidence Loss }\end{array}$}} & 0.31 & 0.28 & 0.15 & 0.10 & 35605 & - \\
\hline & & 0.32 & 0.33 & 0.21 & 0.13 & 35605 & - \\
\hline & & 0.35 & 0.33 & 0.14 & 0.10 & 35605 & - \\
\hline & & 0.19 & 0.17 & 0.23 & 0.13 & 35605 & - \\
\hline \multicolumn{8}{|c|}{ Demographic characteristics } \\
\hline \multirow[t]{2}{*}{ Gender } & Female & 0.33 & 0.31 & 0.16 & 0.10 & 19447 & 54.62 \\
\hline & Male & 0.29 & 0.25 & 0.14 & 0.09 & 16158 & 45.38 \\
\hline \multirow[t]{5}{*}{ Age group } & $15-30$ & 0.30 & 0.28 & 0.16 & 0.10 & 9061 & 25.45 \\
\hline & $31-45$ & 0.32 & 0.31 & 0.16 & 0.10 & 9984 & 28.04 \\
\hline & $46-60$ & 0.32 & 0.31 & 0.16 & 0.09 & 8392 & 23.57 \\
\hline & $61-75$ & 0.30 & 0.28 & 0.14 & 0.07 & 5525 & 15.52 \\
\hline & over 75 & 0.33 & 0.31 & 0.15 & 0.08 & 2643 & 7.42 \\
\hline \multirow[t]{3}{*}{ Education } & no qualification & 0.34 & 0.31 & 0.16 & 0.09 & 6766 & 19.00 \\
\hline & O level - vocational & 0.31 & 0.28 & 0.15 & 0.10 & 19376 & 54.42 \\
\hline & A level - degree & 0.31 & 0.28 & 0.15 & 0.10 & 9463 & 26.58 \\
\hline \multirow[t]{5}{*}{ Marital status } & married - civil partnership & 0.31 & 0.28 & 0.15 & 0.09 & 18382 & 51.63 \\
\hline & separated & 0.37 & 0.33 & 0.20 & 0.11 & 540 & 1.52 \\
\hline & divorced & 0.33 & 0.31 & 0.17 & 0.10 & 3168 & 8.90 \\
\hline & widowed & 0.34 & 0.31 & 0.16 & 0.09 & 2625 & 7.37 \\
\hline & single - never married & 0.30 & 0.28 & 0.16 & 0.10 & 10890 & 30.59 \\
\hline \multirow[t]{5}{*}{ Employment status } & self-employed & 0.29 & 0.28 & 0.13 & 0.08 & 2209 & 6.20 \\
\hline & employed & 0.30 & 0.28 & 0.14 & 0.09 & 18643 & 52.36 \\
\hline & unemployed & 0.36 & 0.33 & 0.19 & 0.07 & 1111 & 3.12 \\
\hline & retired & 0.31 & 0.28 & 0.15 & 0.08 & 7453 & 20.93 \\
\hline & $\begin{array}{l}\text { other (maternity leave, } \\
\text { students, etc.) }\end{array}$ & 0.35 & 0.31 & 0.19 & 0.09 & 6189 & 17.38 \\
\hline \multicolumn{8}{|c|}{ ELSA: PSH and CASP-19 } \\
\hline & PSH & 0.20 & 0.13 & 0.25 & 0.14 & 16656 & - \\
\hline & CASP-19 & 0.27 & 0.25 & 0.16 & 0.06 & 13702 & - \\
\hline
\end{tabular}

Note. Authors' calculations from BHPS and ELSA data. All mental wellbeing indices (GHQ, GHQ subcategories, PSH and CASP-19) vary between zero (least distressed) and one (most distressed). Urban LAs. 
Table 2 - Quarterly crime rates (per 10 thousand population) - Period 2002-2008.

\begin{tabular}{|c|c|c|c|c|c|c|c|c|c|c|c|c|c|c|c|c|}
\hline \multirow[b]{2}{*}{ Crime type } & \multicolumn{8}{|c|}{ England and Wales (375 LAs) } & \multicolumn{8}{|c|}{ Urban areas (188 LAs) } \\
\hline & mean & median & std dev & $\begin{array}{c}\text { within } \\
\text { LA std } \\
\text { dev }\end{array}$ & $\max$ & $\min$ & $\begin{array}{l}\% \text { of } \\
\text { total } \\
\text { crime }\end{array}$ & $\begin{array}{c}\% \text { of } \\
\text { crime in } \\
\text { the } \\
\text { broader } \\
\text { category }\end{array}$ & mean & median & std dev & $\begin{array}{c}\text { within } \\
\text { LA std } \\
\text { dev }\end{array}$ & $\max$ & $\min$ & $\begin{array}{l}\% \text { of } \\
\text { total } \\
\text { crime }\end{array}$ & $\begin{array}{c}\% \text { of } \\
\text { crime in } \\
\text { the } \\
\text { broader } \\
\text { category }\end{array}$ \\
\hline Total Crime & 225.7 & 206.1 & 94.9 & 30.6 & 1074.3 & 16.6 & - & - & 279.8 & 264.9 & 97.1 & 36.9 & 1074.3 & 74.9 & - & - \\
\hline Robbery & 2.9 & 1.3 & 4.5 & 1.2 & 39.3 & 0.0 & 1.3 & 6.4 & 5.0 & 2.9 & 5.5 & 1.6 & 39.3 & 0.0 & 1.8 & 8.6 \\
\hline Sexual Offense & 2.5 & 2.2 & 1.3 & 0.8 & 45.5 & 0.0 & 1.1 & 5.3 & 3.0 & 2.7 & 1.5 & 1.0 & 45.5 & 0.0 & 1.1 & 5.1 \\
\hline Violence & 40.6 & 37.2 & 18.3 & 7.6 & 129.8 & 2.9 & 18.0 & 88.3 & 50.2 & 47.3 & 18.8 & 8.7 & 129.8 & 10.7 & 17.9 & 86.3 \\
\hline Total Violent Crime & 46.0 & 41.2 & 22.3 & 8.0 & 157.6 & 3.2 & 20.4 & 100.0 & 58.2 & 54.2 & 23.3 & 9.2 & 157.6 & 13.3 & 20.8 & 100.0 \\
\hline Burglary & 28.3 & 25.4 & 14.1 & 7.5 & 140.5 & 0.0 & 12.5 & 16.7 & 34.2 & 31.4 & 15.1 & 8.7 & 140.5 & 7.3 & 12.2 & 16.4 \\
\hline Criminal Damage & 49.3 & 46.1 & 18.5 & 7.9 & 148.7 & 3.8 & 21.8 & 29.0 & 57.4 & 54.9 & 18.9 & 9.1 & 148.7 & 17.2 & 20.5 & 27.5 \\
\hline Fraud and Forgery & 9.9 & 8.1 & 7.1 & 4.7 & 149.8 & 0.0 & 4.4 & 5.8 & 12.7 & 10.7 & 8.0 & 5.6 & 69.2 & 0.0 & 4.5 & 6.0 \\
\hline Vehicle Crime & 32.7 & 28.4 & 18.9 & 9.4 & 174.0 & 0.0 & 14.5 & 19.2 & 42.4 & 38.9 & 19.8 & 11.6 & 174.0 & 2.2 & 15.2 & 20.3 \\
\hline Other Theft & 49.7 & 43.1 & 32.4 & 9.2 & 595.3 & 0.0 & 22.0 & 29.2 & 62.5 & 53.0 & 40.1 & 11.2 & 595.3 & 14.4 & 22.3 & 29.9 \\
\hline Total Property Crime & 169.9 & 155.0 & 72.6 & 28.6 & 866.4 & 12.1 & 75.3 & 100.0 & 209.2 & 197.7 & 75.4 & 35.0 & 866.4 & 56.9 & 74.8 & 100.0 \\
\hline Drug Offense & 7.0 & 5.5 & 6.0 & 3.4 & 68.8 & 0.0 & 3.1 & 71.2 & 9.0 & 7.0 & 7.2 & 4.1 & 68.8 & 0.9 & 3.2 & 72.3 \\
\hline Other Crime & 2.8 & 2.5 & 1.7 & 0.9 & 19.4 & 0.0 & 1.3 & 28.8 & 3.4 & 3.2 & 1.7 & 0.9 & 16.7 & 0.0 & 1.2 & 27.7 \\
\hline Total Other Crime & 9.8 & 8.1 & 6.9 & 3.6 & 79.0 & 0.0 & 4.3 & 100.0 & 12.4 & 10.5 & 8.1 & 4.3 & 79.0 & 1.0 & 4.4 & 100.0 \\
\hline
\end{tabular}

Note. Authors' calculations from UK Home Office recorded crime statistics. 
Table 3 - Mental health (GHQ) and crime - FD estimator

\begin{tabular}{|c|c|c|c|c|c|c|}
\hline GHQ & 1 & 2 & 3 & 4 & 5 & 6 \\
\hline & \multicolumn{6}{|c|}{ LA crime } \\
\hline \multirow[t]{2}{*}{$\log$ (total crime rate) } & $0.008^{* *}$ & $0.008^{* *}$ & & & & \\
\hline & {$[0.004]$} & {$[0.004]$} & & & & \\
\hline \multirow[t]{2}{*}{$\log$ (violent crime rate) } & & & 0.001 & 0.001 & & \\
\hline & & & [0.002] & [0.003] & & \\
\hline \multirow[t]{2}{*}{$\log$ (property crime rate) } & & & & & $0.008^{* *}$ & $0.008^{* *}$ \\
\hline & & & & & [0.004] & {$[0.004]$} \\
\hline \multirow[t]{3}{*}{ employment rate (LA) } & $-0.070^{*}$ & $-0.080^{*}$ & -0.066 & $-0.075^{*}$ & -0.067 & $-0.078^{*}$ \\
\hline & {$[0.040]$} & [0.042] & {$[0.040]$} & [0.042] & {$[0.040]$} & [0.042] \\
\hline & \multicolumn{6}{|c|}{ PFA crime } \\
\hline \multirow[t]{2}{*}{$\log$ (total crime rate) } & $0.014^{* * *}$ & $0.014^{* * *}$ & & & & \\
\hline & {$[0.004]$} & {$[0.004]$} & & & & \\
\hline \multirow[t]{2}{*}{$\log$ (violent crime rate) } & & & $0.005^{*}$ & $0.006^{* *}$ & & \\
\hline & & & [0.003] & [0.003] & & \\
\hline \multirow[t]{2}{*}{ log (property crime rate) } & & & & & $0.015^{* * *}$ & $0.015^{* * *}$ \\
\hline & & & & & {$[0.005]$} & [0.005] \\
\hline \multirow[t]{2}{*}{ employment rate (LA) } & $-0.069^{* *}$ & $-0.078^{* *}$ & $-0.067^{* *}$ & $-0.076^{* *}$ & $-0.067^{*}$ & $-0.075^{* *}$ \\
\hline & [0.033] & [0.035] & {$[0.033]$} & {$[0.035]$} & {$[0.034]$} & {$[0.036]$} \\
\hline Individual controls & $X$ & $X$ & $X$ & $X$ & $X$ & $X$ \\
\hline Year-quarter dummies & $X$ & $X$ & $X$ & $x$ & $X$ & $X$ \\
\hline Other LA controls & & $X$ & & $X$ & & $X$ \\
\hline Observations & 25,647 & 25,647 & 25,647 & 25,647 & 25,647 & 25,647 \\
\hline
\end{tabular}

Note. This table reports FD estimates of GHQ index on log crime rates recorded during the quarter before the interview in, respectively, the LA (upper part of the table) or PFA (lower part of the table) of residence. The GHQ index has been normalized to vary between 0 (least distressed) and 1 (most distressed). Other controls are: individual controls (age, age squared, a dummy for children in the household, dummies for marital status, for employment status and for education level, and log household income); a full set of year-quarter dummies; employment rate in the LA of residence (yearly average); other LA controls (share of residents receiving welfare benefits, share of individuals aged 15-24 over total adult population, immigrants share, number of policemen per capita and log population size).

Sample: BHPS data. Urban LAs.

Standard errors: robust and clustered by LA (upper part of the table; 165 clusters) or by PFA (lower part of the table; 41 clusters); ${ }^{*}$ significant at $10 \%$; **significant at $5 \%$; ${ }^{* * *}$ significant at $1 \%$. 
Table 4 - Mental health and crime: disaggregating GHQ into Anxiety, Social Dysfunction and Confidence - FD estimator

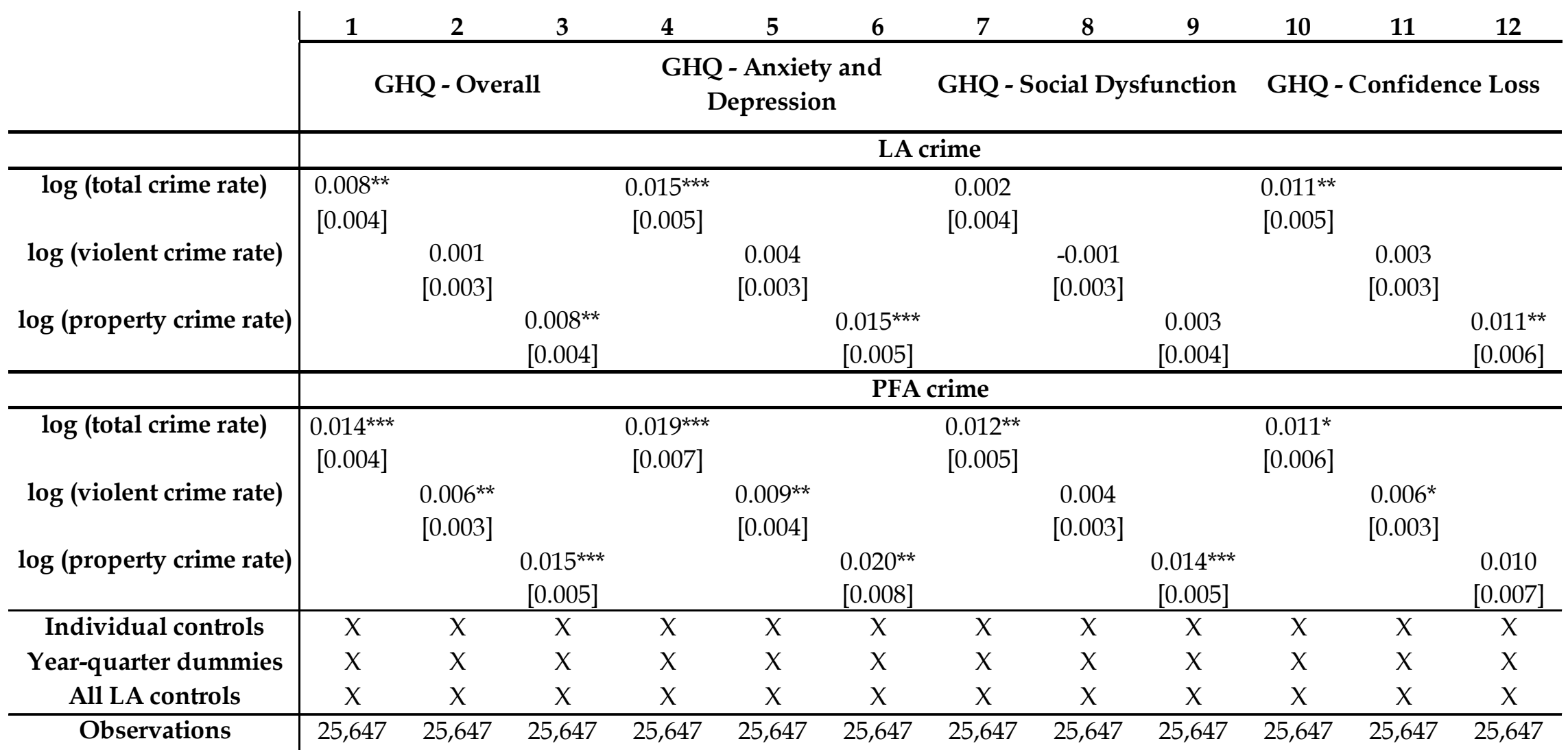

Note. This table reports FD estimates of the four GHQ indices (Overall, Anxiety and Depression, Social Dysfunction; Confidence Loss) on log crime rates recorded during the quarter before the interview in, respectively, the LA (upper part of the table) or PFA (lower part of the table) of residence. All four GHQ indices have been normalized to vary between 0 (least distressed) and 1 (most distressed). Other controls are: individual controls (age, age squared, a dummy for children in the household, dummies for marital status, for employment status and for education level, and log household income); a full set of year-quarter dummies; employment rate in the LA of residence (yearly average); all LA controls (employment rate, share of residents receiving welfare benefits, share of individuals aged 15-24 over total adult population, immigrants share, number of policemen per capita and log population size). Each row reports results from a separate regression, with total crime, violent crime and property crime included alternatively in the regression.

Sample: BHPS data. Urban LAs.

Standard errors: robust and clustered by LA (upper part of the table; 165 clusters) or by PFA (lower part of the table; 41 clusters); ${ }^{*}$ significant at $10 \%$; ${ }^{* *}$ significant at $5 \%$; ${ }^{* * *}$ significant at $1 \%$. 
Table 5 - Mental health (GHQ) and crime: heterogeneous effects - PFA crime

\begin{tabular}{|c|c|c|}
\hline & \multirow{2}{*}{\multicolumn{2}{|c|}{$\begin{array}{cc}1 & 2 \\
& \\
\text { GHQ - Overall }\end{array}$}} \\
\hline & & \\
\hline $\log$ (total crime rate) & $\begin{array}{l}0.008^{*} \\
{[0.004]}\end{array}$ & $\begin{array}{c}0.005 \\
{[0.004]}\end{array}$ \\
\hline $\log ($ total crime rate $) *$ Female & $\begin{array}{l}0.011^{* *} \\
{[0.005]}\end{array}$ & $\begin{array}{l}0.011^{* *} \\
{[0.005]}\end{array}$ \\
\hline $\log ($ total crime rate) $*$ under 30 & & $\begin{array}{c}0.000 \\
{[0.000]}\end{array}$ \\
\hline $\log ($ total crime rate) $*$ over 65 & & $\begin{array}{c}0.000 \\
{[0.000]}\end{array}$ \\
\hline $\log$ (total crime rate) * (A level - degree) & & $\begin{array}{c}0.000 \\
{[0.006]}\end{array}$ \\
\hline $\log ($ total crime rate $) *$ Kids & & $\begin{array}{c}0.010 \\
{[0.007]}\end{array}$ \\
\hline $\log$ (violent crime rate) & $\begin{array}{c}0.001 \\
{[0.003]}\end{array}$ & $\begin{array}{c}-0.003 \\
{[0.003]}\end{array}$ \\
\hline $\log ($ violent crime rate $) *$ Female & $\begin{array}{l}0.008^{* *} \\
{[0.004]}\end{array}$ & $\begin{array}{l}0.008^{* *} \\
{[0.004]}\end{array}$ \\
\hline $\log ($ violent crime rate $) *$ under 30 & & $\begin{array}{c}0.000 \\
{[0.001]}\end{array}$ \\
\hline $\log ($ violent crime rate) $*$ over 65 & & $\begin{array}{c}0.001 \\
{[0.001]}\end{array}$ \\
\hline $\log \left(\right.$ violent crime rate) ${ }^{*}$ (A level - degree $)$ & & $\begin{array}{c}0.006 \\
{[0.005]}\end{array}$ \\
\hline $\log ($ violent crime rate $) *$ Kids & & $\begin{array}{c}0.006 \\
{[0.005]}\end{array}$ \\
\hline $\log$ (property crime rate) & $\begin{array}{l}0.010^{*} \\
{[0.005]}\end{array}$ & $\begin{array}{l}0.008^{*} \\
{[0.005]}\end{array}$ \\
\hline $\log \left(\right.$ property crime rate) ${ }^{*}$ Female & $\begin{array}{l}0.010^{* *} \\
{[0.005]}\end{array}$ & $\begin{array}{l}0.010^{* *} \\
{[0.005]}\end{array}$ \\
\hline $\log ($ property crime rate) $*$ under 30 & & $\begin{array}{c}0.000 \\
{[0.000]}\end{array}$ \\
\hline $\log$ (property crime rate) * over 65 & & $\begin{array}{c}0.000 \\
{[0.000]}\end{array}$ \\
\hline $\log$ (property crime rate) * (A level - degree) & & $\begin{array}{c}-0.004 \\
{[0.005]}\end{array}$ \\
\hline $\log$ (property crime rate) $*$ Kids & & $\begin{array}{c}0.009 \\
{[0.007]}\end{array}$ \\
\hline Individual controls & $\bar{X}$ & $X$ \\
\hline Year-quarter dummies & $x$ & $x$ \\
\hline all LA controls & $x$ & $x$ \\
\hline Observations & 25,647 & 25,647 \\
\hline
\end{tabular}

Note. This table reports FD estimates of GHQ indexes on log crime rates recorded during the quarter before the interview in the PFA of residence. Other controls are: individual controls: age, age squared, a dummy for children in the household, dummies for marital status, for employment status and for education level, and log household income; a full set of year-quarter dummies; employment rate in the LA of residence (yearly average); all LA controls (employment rate, share of residents receiving welfare benefits, share of young adults (individuals aged 15-24 over total adult population), immigrants share, number of policemen per capita and log population size. Total crime, violent crime and property crime (and their respective interactions) are included alternatively in the regression.

Sample: BHPS data. Urban LAs.

Standard errors: robust and clustered by PFA (41 clusters); *significant at $10 \%$; ** significant at $5 \%$; *** significant at $1 \%$. 
Table 6 -Mental health (GHQ) and crime: timing of the effect - PFA crime - FD estimator

\begin{tabular}{|c|c|c|c|c|c|c|c|c|c|c|}
\hline GHQ & 1 & 2 & 3 & 4 & 5 & 6 & 7 & 8 & 9 & 10 \\
\hline & \multicolumn{10}{|c|}{ PFA crime } \\
\hline $\log$ (total crime rate) - quarter $Q$ & $\begin{array}{l}0.013^{* *} \\
{[0.005]}\end{array}$ & & & & & & $\begin{array}{c}0.013 \\
{[0.009]}\end{array}$ & & & \\
\hline $\log$ (total crime rate) - quarter Q-1 & & $\begin{array}{l}0.012^{*} \\
{[0.006]}\end{array}$ & & & & & $\begin{array}{c}0.000 \\
{[0.009]}\end{array}$ & & & \\
\hline $\log$ (total crime rate) - quarter Q-2 & & & $\begin{array}{l}0.012^{* *} \\
{[0.005]}\end{array}$ & & & & $\begin{array}{c}0.009 \\
{[0.009]}\end{array}$ & & & \\
\hline $\log$ (total crime rate) - quarter Q-3 & & & & $\begin{array}{c}0.001 \\
{[0.006]}\end{array}$ & & & $\begin{array}{l}-0.005 \\
{[0.008]}\end{array}$ & & & \\
\hline $\log$ (total crime rate) - quarter $Q+1$ & & & & & $\begin{array}{c}0.009 \\
{[0.006]}\end{array}$ & & $\begin{array}{l}-0.006 \\
{[0.012]}\end{array}$ & & & \\
\hline $\log$ (total crime rate) - quarter $Q+2$ & & & & & & $\begin{array}{c}0.001 \\
{[0.006]}\end{array}$ & $\begin{array}{l}-0.000 \\
{[0.008]}\end{array}$ & & & \\
\hline $\log$ (total crime rate) - $\operatorname{avg}(Q, Q-1)$ & & & & & & & & $\begin{array}{l}0.015^{\star *} \\
{[0.006]}\end{array}$ & $\begin{array}{l}0.015^{* *} \\
{[0.007]}\end{array}$ & $\begin{array}{l}0.017^{* *} \\
{[0.008]}\end{array}$ \\
\hline $\log ($ total crime rate) - avg (Q-2, Q-3) & & & & & & & & & $\begin{array}{l}-0.000 \\
{[0.006]}\end{array}$ & $\begin{array}{c}-0.001 \\
{[0.007]}\end{array}$ \\
\hline $\log$ (total crime rate) - avg $(Q+1, Q+2)$ & & & & & & & & & & $\begin{array}{l}-0.003 \\
{[0.007]} \\
\end{array}$ \\
\hline Individual controls & $X$ & $X$ & $\mathrm{X}$ & $\mathrm{X}$ & $x$ & $\mathrm{X}$ & $\mathrm{X}$ & $\mathrm{x}$ & $\mathrm{X}$ & $X$ \\
\hline Year-quarter dummies & $X$ & $X$ & $X$ & $x$ & $x$ & $x$ & $\mathrm{X}$ & $X$ & $\mathrm{X}$ & $x$ \\
\hline $\begin{array}{c}\text { All LA controls } \\
\end{array}$ & $\mathrm{X}$ & $X$ & $X$ & $X$ & $\mathrm{X}$ & $X$ & $\mathrm{X}$ & $\mathrm{X}$ & $\mathrm{X}$ & $\mathrm{X}$ \\
\hline Observations & 20,307 & 20,307 & 20,307 & 20,307 & 20,307 & 20,307 & 20,307 & 20,307 & 20,307 & 20,307 \\
\hline
\end{tabular}

Note. This table reports FD estimates of GHQ index on log total crime rates recorded during the months before the interview in the PFA of residence. The GHQ index has been normalized to vary between 0 (least distressed) and 1 (most distressed). In the table, we define as "quarter Q" the last quarter before the interview (i.e. our main measure of crime throughout the paper), while lags (leads) of crime rate are defined as, $\mathrm{Q}-1, \mathrm{Q}-2, \ldots(\mathrm{Q}+1, \mathrm{Q}+2, \ldots)$. Other controls are: individual controls (age, age squared, a dummy for children in the household, dummies for marital status, for employment status and for education level, and log household income); a full set of year-quarter dummies; all LA controls (employment rate, share of residents receiving welfare benefits, share of individuals aged 15-24 over total adult population, immigrants share, number of policemen per capita and log population size).

Sample: BHPS data. Urban LAs.

Standard errors: robust and clustered by PFA (41 clusters); *significant at $10 \% ; * *$ significant at $5 \% ; * *$ significant at $1 \%$. 


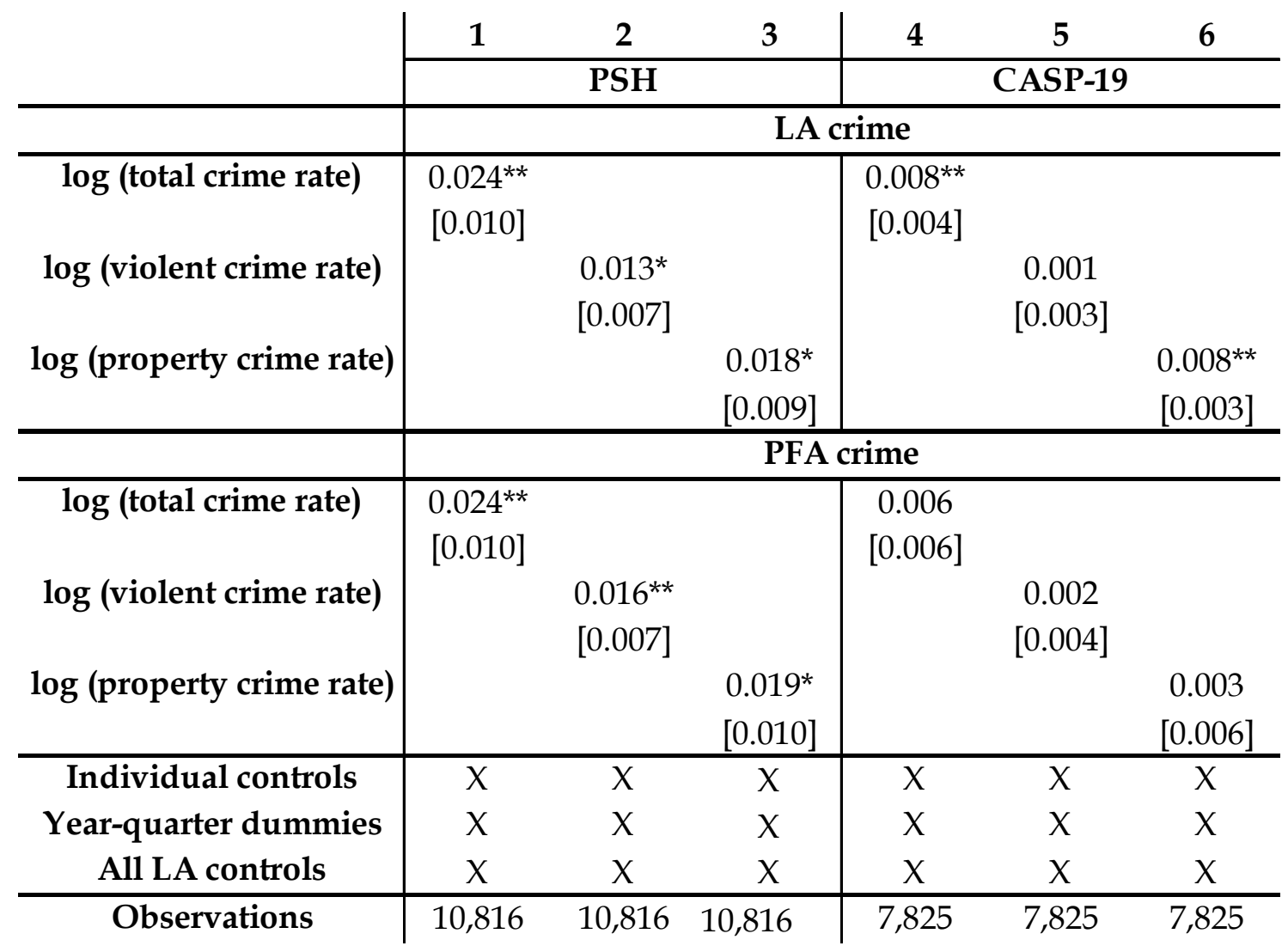

Note. This table reports FD estimates of PSH and CASP-19 indexes on log crime rates recorded during the quarter before the interview in the LA (upper part of the table) or PFA (lower part of the table) of residence. Both indices have ben normalized to vary betwe 0 (least distressed) and 1 (most distressed). Other controls are individual controls (age, age squared, a dummy for children in the household, dummies for maita Bto status, or employme stat share of residents receiving welfare benefits, share of individuals aged 15-24 over total adult population, immigrants share, number of policemen per capita and log population size). Each row reports estimation results from separate regressions, with each type of crime included alternatively in the regression.

Sample: ELSA data. Urban LAs.

Standard errors: robust and clustered by LA (upper part of the table; 165 clusters) or by PFA (lower part of the table; 41 clusters); ${ }^{*}$ significant at $10 \%$; ** significant at $5 \%$; ${ }^{* * *}$ significant at $1 \%$. 
Table 8 - The impact of 2005 London Bombings on mental health: DID estimates

\begin{tabular}{|c|c|c|c|c|c|c|}
\hline & 1 & 2 & 3 & 4 & 5 & 6 \\
\hline & GHQ & $\begin{array}{c}\text { GHQ } \\
\text { (residual) }\end{array}$ & $\begin{array}{c}\text { GHQ } \\
\text { (residual) }\end{array}$ & $\begin{array}{c}\text { GHQ - } \\
\text { Anxiety and } \\
\text { Depression } \\
\text { (residual) }\end{array}$ & $\begin{array}{c}\text { GHQ - } \\
\text { Social } \\
\text { Dysfunction } \\
\text { (residual) } \\
\end{array}$ & $\begin{array}{c}\text { GHQ - } \\
\text { Confidence } \\
\text { Loss } \\
\text { (residual) } \\
\end{array}$ \\
\hline & \multicolumn{2}{|c|}{2004 Vs 2005} & \multicolumn{4}{|c|}{2004 Vs 2005 (only Sept) } \\
\hline \multirow[b]{2}{*}{ After July * Year 2005} & \multicolumn{6}{|c|}{ All LAs } \\
\hline & $\begin{array}{c}0.012 \\
{[0.016]} \\
\end{array}$ & $\begin{array}{c}0.013 \\
{[0.016]} \\
\end{array}$ & $\begin{array}{c}0.012 \\
{[0.016]}\end{array}$ & $\begin{array}{c}0.015 \\
{[0.024]}\end{array}$ & $\begin{array}{c}0.009 \\
{[0.013]}\end{array}$ & $\begin{array}{c}0.012 \\
{[0.024]}\end{array}$ \\
\hline Observations & 17,790 & 17,790 & 9,158 & 9,158 & 9,158 & 9,158 \\
\hline \multirow[b]{2}{*}{ After July * Year 2005} & \multicolumn{6}{|c|}{ Main 20 cities } \\
\hline & $\begin{array}{l}0.069^{* *} \\
{[0.032]}\end{array}$ & $\begin{array}{l}0.070^{* *} \\
{[0.033]}\end{array}$ & $\begin{array}{l}0.073^{* *} \\
{[0.032]}\end{array}$ & $\begin{array}{l}0.096^{* *} \\
{[0.046]} \\
\end{array}$ & $\begin{array}{l}0.058^{*} \\
{[0.030]} \\
\end{array}$ & $\begin{array}{c}0.072 \\
{[0.058]} \\
\end{array}$ \\
\hline Observations & 3,421 & 3,421 & 1,766 & 1,766 & 1,766 & 1,766 \\
\hline \multirow[b]{2}{*}{ After July * Year 2005} & \multicolumn{6}{|c|}{ Main 5 cities } \\
\hline & $\begin{array}{l}0.093^{* *} \\
{[0.038]}\end{array}$ & $\begin{array}{l}0.098^{* *} \\
{[0.037]}\end{array}$ & $\begin{array}{l}0.096^{* *} \\
{[0.035]}\end{array}$ & $\begin{array}{c}0.142^{\star * *} \\
{[0.052]} \\
\end{array}$ & $\begin{array}{l}0.076^{\star *} \\
{[0.037]} \\
\end{array}$ & $\begin{array}{c}0.059 \\
{[0.055]} \\
\end{array}$ \\
\hline Observations & 2,006 & 2,006 & 1,063 & 1,063 & 1,063 & 1,063 \\
\hline \multirow[b]{2}{*}{ After July * Year 2005} & \multicolumn{6}{|c|}{ London (inner and outer) } \\
\hline & $\begin{array}{l}0.100^{* *} \\
{[0.038]}\end{array}$ & $\begin{array}{c}0.106^{\star * *} \\
{[0.039]}\end{array}$ & $\begin{array}{c}0.103^{* * *} \\
{[0.037]}\end{array}$ & $\begin{array}{l}0.141^{* *} \\
{[0.054]}\end{array}$ & $\begin{array}{l}0.089^{* *} \\
{[0.042]}\end{array}$ & $\begin{array}{c}0.069 \\
{[0.059]}\end{array}$ \\
\hline Observations & 1,262 & 1,262 & 695 & 695 & 695 & 695 \\
\hline
\end{tabular}

Note. This table reports DID estimates of the impact of the 2005 London Bombings on GHQ index (and its subcategories) of respondents. The dummy variable "Year2005" is equal to one if the interview was carried out in 2005 (rather than in 2004) and identifies the treatment group. The dummy "After July" is equal to one if the interview took place after July and identifies the "treatment". In columns 1-2, this includes individuals interviewed between September and December (included), while in columns 3-6 we restrict it only to interviews collected in September. The table reports the coefficient estimated on the interaction between the "Year2005" dummy and the "After July" dummy, which is equal to one for those individuals interviewed after July in 2005. The GHQ indices have been normalized to vary between 0 (least distressed) and 1 (most distressed). Residual GHQ measures are obtained computing the residuals after regressing GHQ measures on individual characteristics (gender, age, age squared, a dummy for children in the household, dummies for marital status, for employment status and for education level, and log household income), Local Authority fixed effects and year and month dummies. Main 20 cities are: Birmingham, Bradford, Bristol, Cardiff, Coventry, Derby, Kingston-upon-Hull, Leeds, Leicester, Liverpool, London, Manchester, Newcastle upon Tyne, Nottingham, Plymouth, Sheffield, Southampton, Stoke-on-Trent, Swansea, and Wolverhampton. Main 5 cities are: Birmingham, Bradford, Leeds, London and Sheffield. London (inner and outer) includes 33 LAs. Each cell reports estimation results from a separate regression.

Sample: BHPS data. Years 2004-2005.

Standard errors: robust and clustered by LA; *significant at $10 \%$; ** significant at $5 \%$; ** significant at $1 \%$. 


\section{Appendix}

\section{A1 Measures of mental health}

\section{A1.1 BHPS: The General Health Questionnaire (GHQ-12)}

The GHQ-12 questionnaire administered in the BHPS is as follows:

\section{Table A 1 - GHQ-12 questionnaire}

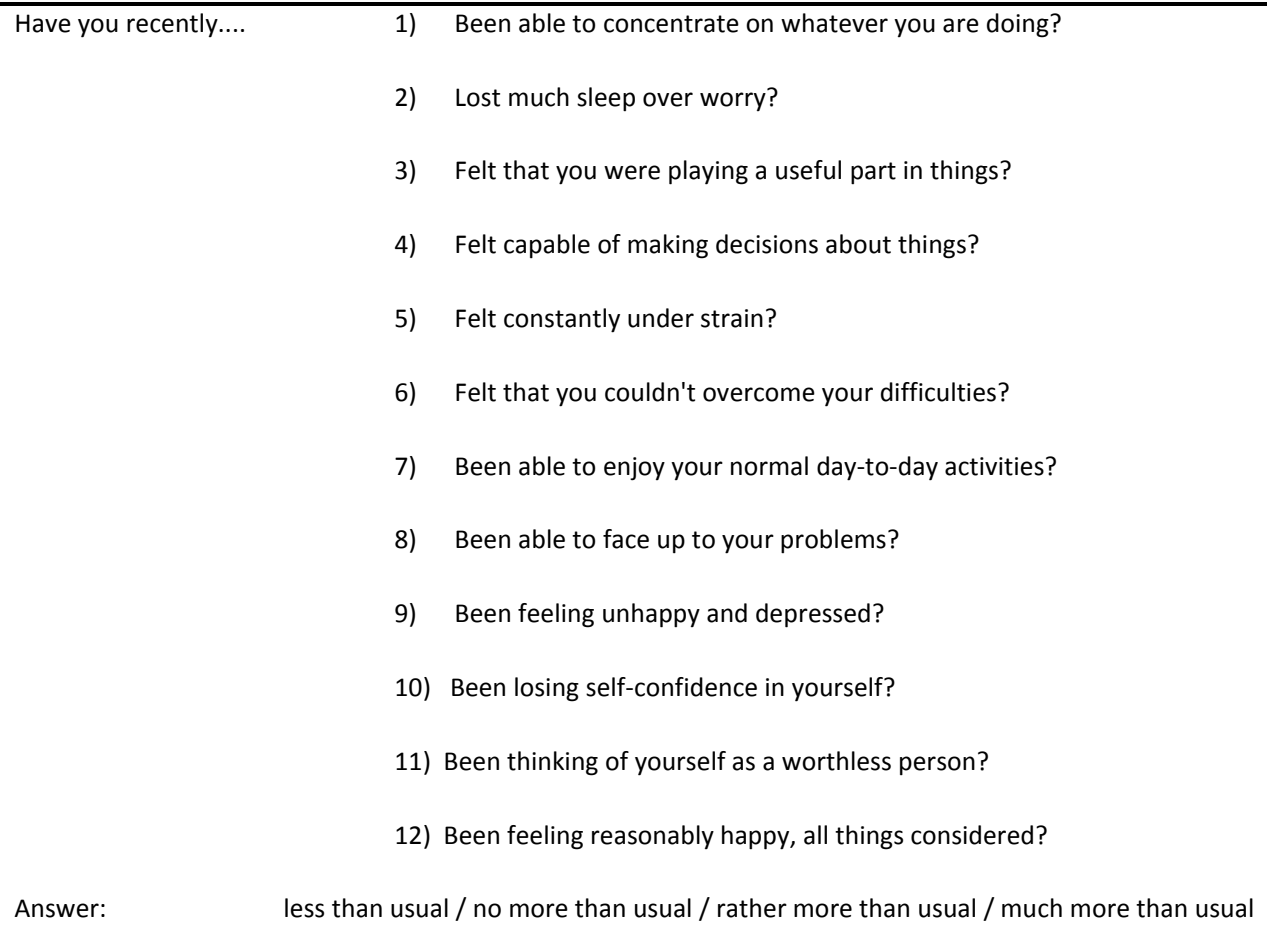

While the longer versions of the GHQ are normally considered multidimensional, the GHQ- 12 is often regarded as measuring only a single dimension of psychological health. However, several authors suggested that the GHQ-12 contained two or three clinically meaningful factors. Following Graetz's (1991) disaggregation of GHQ-12 into three factors - a) anxiety and depression; b) social dysfunction; c) loss of confidence) - GHQ-12 questions can be grouped in the following way:

Table A 2 - GHQ-12 disaggregation

\begin{tabular}{|ll|}
\hline 2) Lost much sleep over worry? \\
Anxiety and depression & 5) Felt constantly under strain? \\
& 6) Felt that you couldn't overcome your difficulties? \\
9) Been feeling unhappy and depressed?
\end{tabular}




\begin{tabular}{l}
\begin{tabular}{l} 
1) Been able to concentrate on whatever you are doing? \\
3) Felt that you were playing a useful part in things? \\
4) Felt capable of making decisions about things? \\
7) Been able to enjoy your normal day-to-day activities? \\
8) Been able to face up to your problems? \\
12) Been feeling reasonably happy, all things considered? \\
\hline 10) Been losing self-confidence in yourself? \\
11) Been thinking of yourself as a worthless person?
\end{tabular} \\
\hline
\end{tabular}

\section{A1.2 Measures of mental health in ELSA}

\section{A1.2.1 ELSA Psychosocial Health Module (PSH)}

The ELSA Psychosocial Health Module (PSH) assesses symptoms of depression, based on the Centre for Epidemiologic Studies Depression Scale (CES-D), which is one of the most common screening tests for helping an individual to determine his or her depression quotient (Radloff, 1977). Interviewees are asked whether they recently had symptoms of depression (felling of unhappiness, loneliness, fatigue, etc.). An index of depression can be constructed by assigning one point for each positive answer (and zero for negative ones). The measure ranges between 0 (least distressed) and 8 (most distressed). In our empirical analysis we normalize the variable to range between 0 (least distressed) and 1 (most distressed).

The PSH questions in ELSA are the following:

Table A 3 - Psychosocial Health Module (PSH)

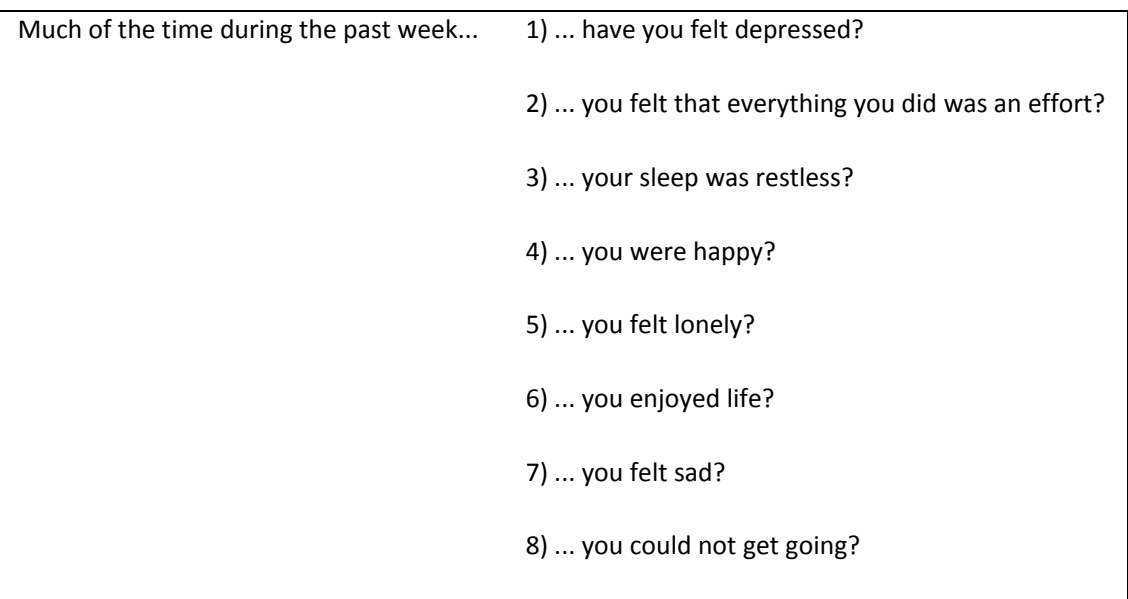




\section{A1.2.2 CASP-19}

The ELSA contains also a theory-based measure of the quality of life of older adults which consists of 19 questions (CASP-19). Although this latter measure is not exactly conceived as an index of mental wellbeing, it measures perceived general wellbeing of respondents which should reflect also their level of mental distress. Indeed, the type of questions asked to measure GHQ, PSH and CASP-19 are very similar in nature.

CASP-19 is a theory-based measure of the quality of life of older adults (Hyde et al., 2003), which consists of 19 questions (CASP-19). Although this latter measure is not exactly conceived as an index of mental wellbeing, it measures perceived general wellbeing of respondents which should reflect also their level of mental distress. Indeed, the type of questions asked to measure GHQ, PSH and CASP-19 are very similar in nature (compare Table A 1, Table A 3 and Table A 4). The CASP-19 questions cover four theoretical domains: a) Control: the ability to intervene actively in one's own environment; b) Autonomy: the feeling of an individual to be free from unwanted interference by others; c) Self-realisation: the active processes of human fulfilment; d) Pleasure: the sense of fun derived from the more active aspects of life.

The CASP-19 measure takes account of whether or how often (often, sometimes, not often or never) statements on the four domains of quality of life apply to older people. A scale is created that ranges from 0 , which represents total satisfaction on all domains, to 57 , which represents a complete absence of quality of life. In our empirical analysis we adopt the Likert scoring method and we normalize the variable to range between 0 (least distressed) and 1 (most distressed). The CASP-19 questionnaire is the following:

Table A 4 - CASP-19

Control
$\begin{aligned} & \text { 2) I I feel that what happens to me is out of my control } \\ & \text { 3) I feel free to plan for the future } \\ & \text { 4) I feel left out of things } \\ & \text { 5) I can do the things that I want to do } \\ & \text { 6) Family responsibilities prevent me from doing what I want to do } \\ & \text { 7) I feel that I can please myself what I do }\end{aligned}$




\begin{tabular}{|l} 
8) My health stops me from doing things I want to do \\
9) Shortage of money stops me from doing the things I want to do \\
\hline 10) I look forward to each day \\
11) I feel that my life has meaning \\
12) I enjoy the things that I do \\
$\begin{array}{l}\text { 13) I enjoy being in the company of others } \\
\text { 14) On balance, I look back on my life with a sense of happiness } \\
\text { 15) I feel full of energy these days } \\
\text { 16) I choose to do things that I have never done before } \\
\text { 17) I feel satisfied with the way my life has turned out } \\
\text { 18) I feel that life is full of opportunities } \\
\text { 19) I feel that the future looks good for me }\end{array}$
\end{tabular}

\section{A2 Identification and empirical issues}

We estimate the following regression, where, we have written the region index $r$ as a function of the individual $\mathrm{i}$ and time $\mathrm{t}$, and where the dependent variable $\widetilde{M D}_{i r(i, t) t}$ are the residuals after time changing region- and individual characteristics, and time dummies have been netted out:

$$
\widetilde{M D}_{i r(i, t) t}=a_{0}+a_{1} C R_{r(i, t) t}+L A_{r(i, t)}+\eta_{i}+u_{i r(i, t) t}
$$

Suppose we estimate this equation in First Differences. For individuals who do not move across LAs, the FD transformation removes both the LA and individual fixed effects:

$$
\Delta \widetilde{M D} \operatorname{ir}(i, t) t=a_{1} \Delta C R_{r(i, t) t}+\Delta u_{i r(i, t) t}
$$

The parameter $\alpha_{1}$ can be consistently estimated given that $\operatorname{cov}\left(\Delta C R_{r(i, t) t}, \Delta u_{i r(i, t) t}\right)=0$. For individuals who moved from region $r$ to region $r^{\prime}$, instead, we have:

$$
\widetilde{M D}_{i r^{\prime}(i, t) t}-\widetilde{M D}_{i r(i, t-1) t-1}=a_{1}\left(C R_{r^{\prime}(i, t) t}-C R_{r(i, t-1) t-1}\right)+\left(\varepsilon_{i r^{\prime}(i, t) t}-\varepsilon_{i r(i, t-1) t-1}\right)
$$

where: $\varepsilon_{i r^{\prime}(i, t) t}=L A_{r^{\prime}(i, t)}+u_{i r^{\prime}(i, t) t}$ and $\varepsilon_{i r(i, t-1) t-1}=L A_{r(i, t-1)}+u_{i r(i, t-1) t-1}$.

Therefore, first differencing will only eliminate the area fixed effects for non-movers, while for movers the error term contains the difference in the area fixed effects of the two locations, which may be correlated with the difference in crime rates across the two locations. This will introduce a bias in our estimates whose sign is ambiguous (it depends on the relative size of the correlations between crime realizations and LA fixed effects within and across areas). 
The main strategy we employ to address this identification problem is to consider an individual as a different individual in each area of residence, with a different individual fixed effect. We thus only use observations when the respondent has spent two consecutive periods in the same area. However, this approach may introduce some selection bias in our estimation: if moving decisions are affected by past crime rates, individuals who did not move in response to a given realization of crime must have received shocks to their moving decision different from those who moved somewhere else. If shocks to mental distress and to moving decisions are correlated, this will potentially bias our estimates.

To see this, we start by modelling the moving decision. An individual $i$ living in area $r$ in time period $t$ will move away $\left(m_{i r t}=1\right)$ from that area if her level of unobserved dislike for the area $\left(m^{*}{ }_{i r t}\right)$ is above a certain threshold $\bar{m}_{i}$. Suppose that the moving decision in one period depends on the level of crime recorded in the region in the previous period:

$$
\begin{aligned}
& m_{i r t}=1 \text { if } m_{i r t}^{*}>\bar{m}_{i} \\
& m_{i r t}^{*}=\beta_{0}+\beta_{1} C R_{r t-1}+\phi_{i}+v_{i r t}
\end{aligned}
$$

Now, when estimating equation (1A) using only "stayers", we obtain consistent estimates if:

$$
\begin{aligned}
& E\left[\left(C R_{i r t}-C R_{i r t}\right)\left(u_{i r t}-u_{i r t-1}\right) \mid m_{i r t}=m_{i r t-1}=0\right]= \\
& =E\left[\left(C R_{i r t}-C R_{i r t}\right)\left(u_{i r t}-u_{i r t-1}\right) \mid v_{i r t} \leq \bar{m}_{i}-\beta_{0}-\beta_{1} C R_{r t-1}-\phi_{i} ; v_{i r t-1} \leq \bar{m}_{i}-\beta_{0}-\beta_{1} C R_{r t-2}-\phi_{i}\right]=0
\end{aligned}
$$

This is the case if shocks to dissatisfaction with the area and to mental distress are not correlated (i.e. $\left.E\left(u_{i r t}, v_{i r t}\right)=0\right)$. Note that this allows the unobserved individual-specific term $\eta_{i}$ in equation $(1 \mathrm{~A})$ to be correlated with the term $\phi_{i}$ in equation $(3 \mathrm{~A})$, which should eliminate most sources of correlation due to individual specific heterogeneity. However, if moving decisions are affected by past crime rates (i.e. $\beta_{1} \neq 0$ ), and if $u_{i r t}$ and $v_{i r t}$ are correlated, then estimates based on "stayers" may be biased. The sign of the bias depends on the correlation between the shocks $u_{i r t}$ and $v_{i r t}$. Assume that shocks affecting area dislike are positively correlated with shocks that determine mental distress. Now suppose that crime was very high in area $r$ in the last period. People who decide not to move away from area $r$ must have experienced a low shock $v_{\text {irt }}$ to their level of dislike of the area in the current period. By focusing only on "stayers" we may thus create a negative correlation between $C R_{r t-1}$ and $v_{i r t}$. If $u_{i r t}$ and $v_{i r t}$ are positively correlated, this implies a negative 
correlation between $C R_{r t-1}$ and $u_{i r t}$ which can potentially create an upward bias in our estimates. Indeed, if we compute:

$$
\begin{aligned}
E\left(\Delta C R_{r t}, \Delta u_{i r t}\right. & \left.\mid m_{i r t}=m_{i r t-1}=0\right) \\
= & E\left(C R_{r t}, u_{i r t} \mid m_{i r t}=m_{i r t-1}=0\right)-E\left(C R_{r t}, u_{i r t-1} \mid m_{\text {irt }}=m_{\text {irt }-1}=0\right) \\
& -E\left(C R_{r t-1}, u_{i r t} \mid m_{\text {irt }}=m_{\text {irt-1 }}=0\right)+E\left(C R_{r t-1}, u_{i r t-1} \mid m_{\text {irt }}=m_{\text {irt }-1}=0\right)
\end{aligned}
$$

even if the first, second and last term in the summation are equal to zero, the third conditional covariance is negative $E\left(C R_{r t-1}, u_{i r t} \mid m_{i r t}=m_{i r t-1}=0\right)$. This implies that:

$$
E\left(\Delta C R_{r t}, \Delta u_{\text {irt }} \mid m_{\text {irt }}=m_{\text {irt }-1}=0\right)>0
$$

Therefore, if moving decisions are actually affected by past crime rates (i.e. $\beta_{1} \neq 0$ ), and if $u_{\text {irt }}$ and $v_{i r t}$ are positively correlated, our estimates may be upward biased.

As we discuss in section 3, we consider this a minor concern given that crime-related moving decisions do not seem particularly relevant in our data.

Indeed, in the online appendix B1 we use an IV strategy to deal with this potential concern, where we instrument the crime rate to which movers are exposed to with the contemporaneous crime rate in the area where they resided in the first wave. The estimation results of this alternative strategy fully confirm our main results. 


\section{A3 Appendix figures}

Figure A 1 - Concern about crime and risky behaviour, rating of local police and local crime, by PFA; BCS data (2004-2008)
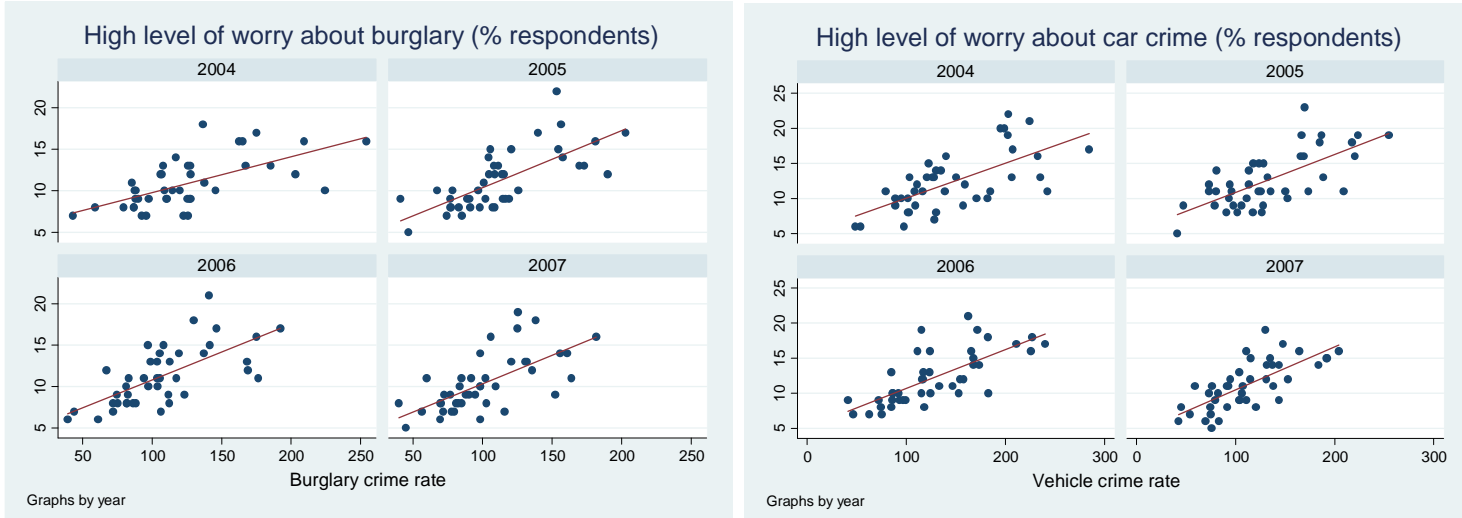

High level of worry about violent crime (\% respondents)

High level of perceived drug use or dealing (\% respondents)
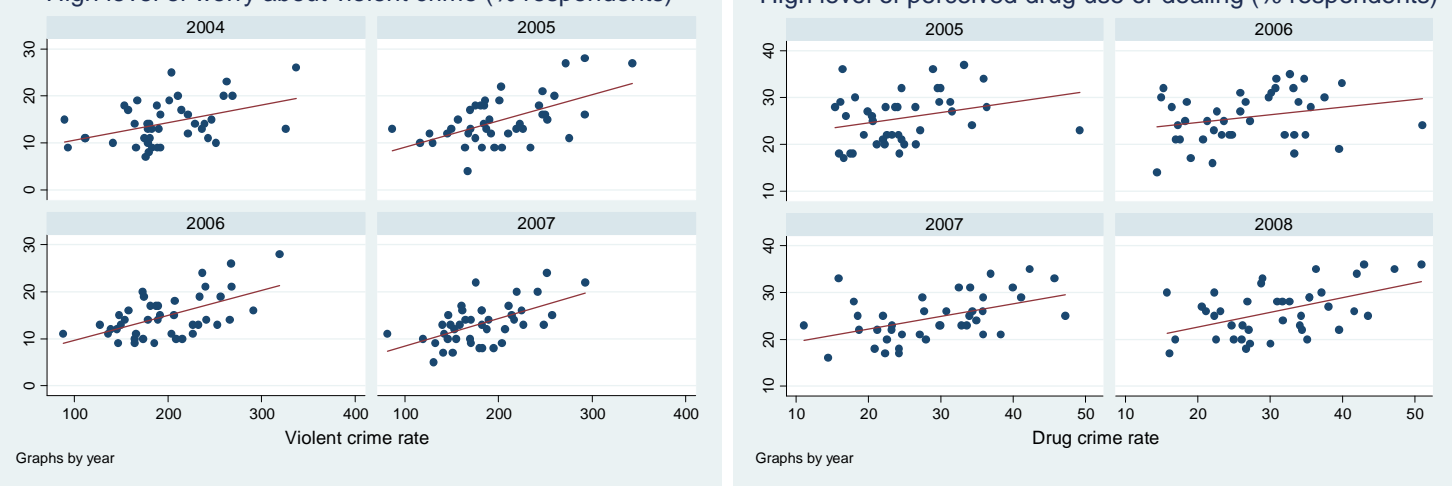

High level of perceived anti-social behaviour(\% respondents)
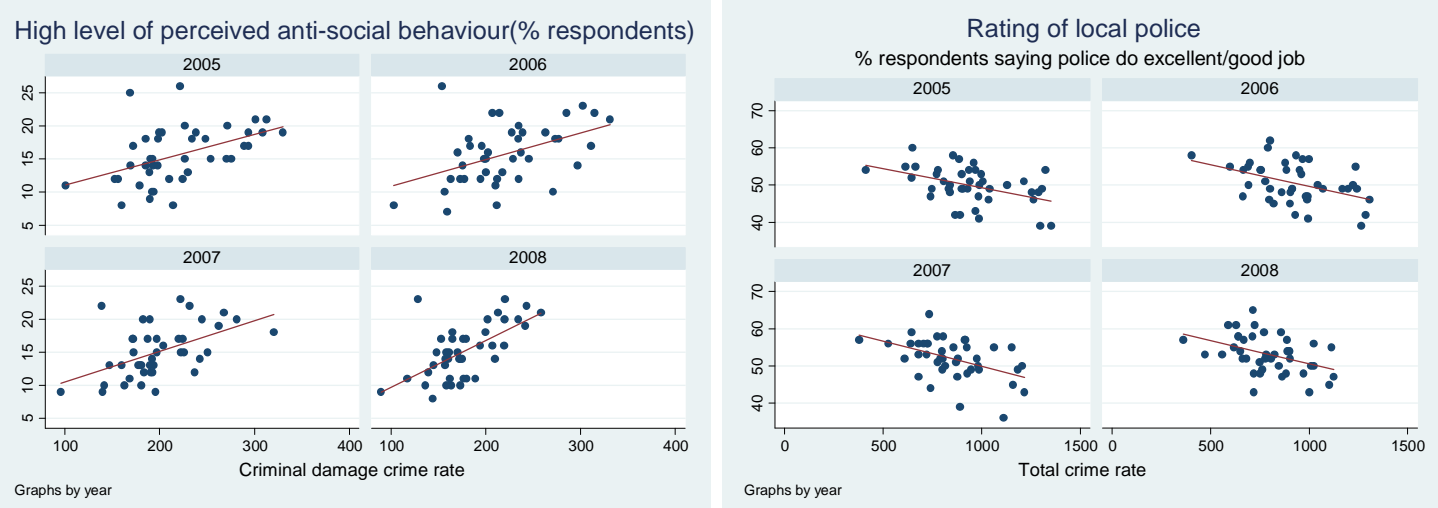

Note. Authors' calculations from British Crime Survey (BCS) data and UK Home Office recorded crime statistics. 


\section{A4 Appendix Tables}

\section{Table AA 1 - Crime categories: definitions and crime sub-categories list}

\begin{tabular}{|c|c|c|c|}
\hline & Crime type & Definition & Crime list (subcategories) \\
\hline \multirow{3}{*}{ 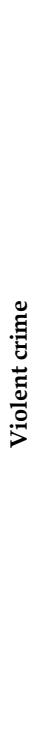 } & Robbery & $\begin{array}{l}\text { A robbery is an incident or offence in which force or the } \\
\text { threat of force is used either during or immediately } \\
\text { prior to a theft or attempted theft. As with violence } \\
\text { against the person, police recorded robberies cover a } \\
\text { wide range of seriousness from armed bank robberies } \\
\text { to muggings for mobile phones or small amounts of } \\
\text { money. }\end{array}$ & 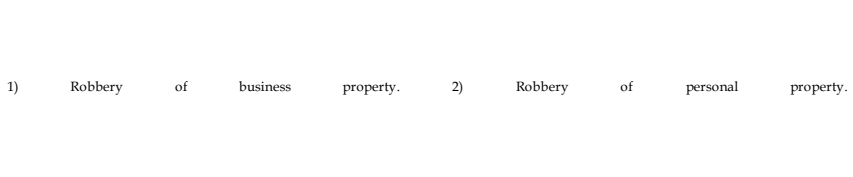 \\
\hline & Sexual offences & 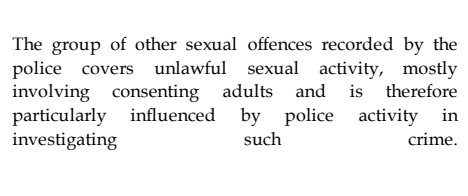 & 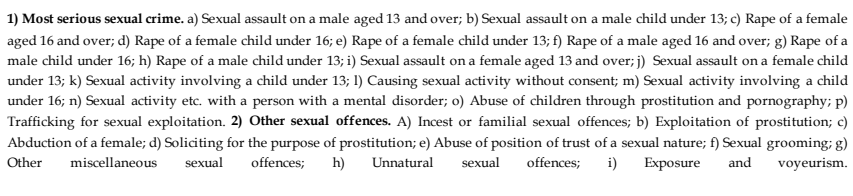 \\
\hline & $\begin{array}{c}\text { Violence } \\
\text { (Violence against } \\
\text { the person) }\end{array}$ & $\begin{array}{l}\text { Violence against the person offences contain the full } \\
\text { spectrum of assaults, from pushing and shoving that } \\
\text { result in no physical harm, to murder. Even within the } \\
\text { same offence classification, the degree of violence } \\
\text { varies considerably between incidents. }\end{array}$ & 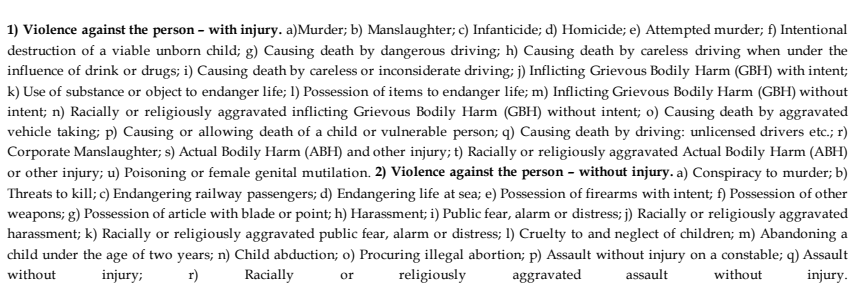 \\
\hline \multirow{5}{*}{ 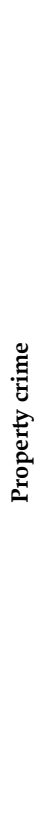 } & Burglary & $\begin{array}{l}\text { The police record an offence of burglary if a person } \\
\text { enters any building as a trespasser and with intent to } \\
\text { commit an offence of theft, Grievous Bodily Harm } \\
\begin{array}{lll}(\mathrm{GBH}) \quad \text { or } \quad \text { unlawful } \quad \text { damage. }\end{array}\end{array}$ & $\begin{array}{l}\text { a) Burglary in a dwelling; b) Attempted burglary in a dwelling; c) Distraction burglary in a dwelling; d) Attempted distraction burglary } \\
\text { in a dwelling; e) Aggravated burglary in a dwelling; } f \text { Burglary in a building other than a dwelling; } g \text { ) Attempted burglary in a building } \\
\text { other } \\
\begin{array}{lllllllll}\text { than } & \text { a dwelling; } & \text { h) Agravated } & \text { burglary } & \text { in a building } & \text { other } & \text { than a dwelling. }\end{array}\end{array}$ \\
\hline & Criminal damage & $\begin{array}{l}\text { Police recorded criminal damage results from any } \\
\text { person who without lawful excuse destroys or } \\
\text { damages any property belonging to another, intending } \\
\text { to destroy or damage any such property or being } \\
\text { reckless as to whether any such property would be } \\
\text { destroyed or damaged. }\end{array}$ & 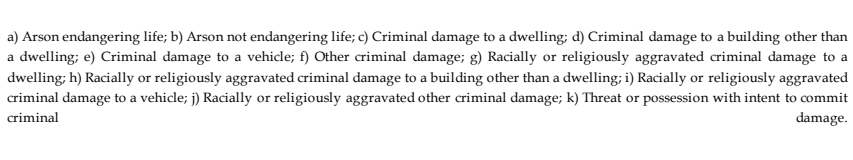 \\
\hline & $\begin{array}{l}\text { Fraud and } \\
\text { Forgery }\end{array}$ & $\begin{array}{l}\text { Under the Fraud Act 2006, fraud is defined as } \\
\text { dishonestly making a false representation to obtain } \\
\text { property or money for themselves or another. }\end{array}$ & 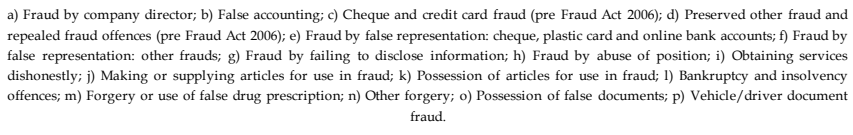 \\
\hline & $\begin{array}{c}\text { Vehicle crime } \\
\text { (Offences against } \\
\text { vehicles) }\end{array}$ & $\begin{array}{l}\text { The police recorded crime category of offences against } \\
\text { vehicles covers private and commercial vehicles } \\
\text { (although does not distinguish between the two). }\end{array}$ & $\begin{array}{l}\text { a) Aggravated vehicle taking; b) Theft from a vehicle; c) Theft or unauthorised taking of motor vehicle; d) Interfering with a motor } \\
\text { vehicle. }\end{array}$ \\
\hline & Other theft & $\begin{array}{l}\text { The recorded crime offence group of other theft } \\
\text { offences covers thefts that are not covered by other } \\
\text { property crime offence groups (i.e. thefts from vehicles } \\
\text { is included in offences against vehicles). }\end{array}$ & $\begin{array}{l}\text { a) Profiting from or concealing knowledge of the proceeds of crime; b) Theft from the person; c) Theft in a dwelling other than from } \\
\text { automatic machine or meter; d) Theft by an employee; e) Theft of mail; f) Dishonest use of electricity; g) Theft or unauthorised taking of a } \\
\text { pedal cycle; h) Shoplifting; i) Theft from automatic machine or meter; j) Other theft or unauthorised taking; } k \text { ) Handling stolen goods. }\end{array}$ \\
\hline \multirow{2}{*}{ 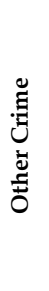 } & Drug offences & $\begin{array}{l}\text { Recorded crime figures for drugs offences refer to any } \\
\text { act involvning trafficking, delaing and possession of } \\
\text { illicit drugs }\end{array}$ & $\begin{array}{l}\text { a) Trafficking in controlled drugs; b) Other drug offences; c) Possession of controlled drugs (excluding cannabis); d) Possession of } \\
\text { controlled } \\
\text { drugs } \\
\text { (cannabis). }\end{array}$ \\
\hline & Any other crime & miscellaneous & 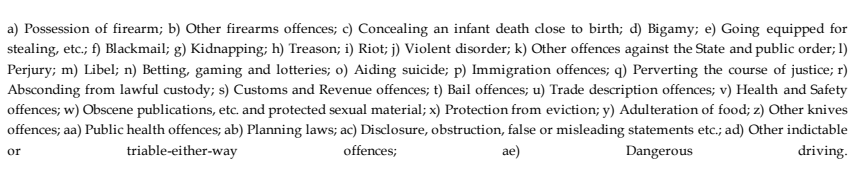 \\
\hline
\end{tabular}

Source. Home Office: $\underline{\text { http://rds.homeoffice.gov.uk/rds/pdfs10/crimestats-userguide.pdf }}$ 
Table AA 2 - Mental health (GHQ) and crime: individual and LA controls

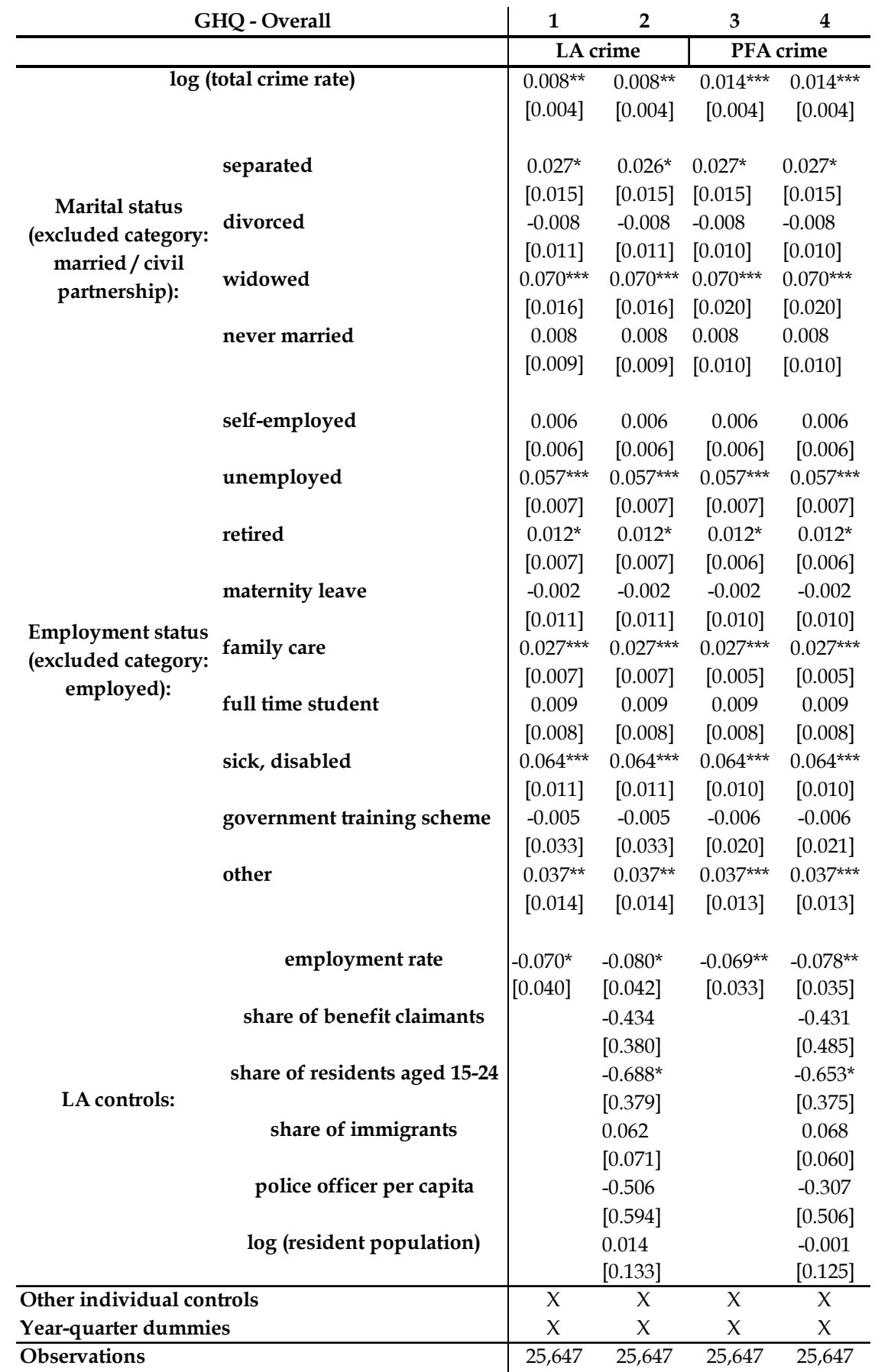

Note. This table reports FD estimates of GHQ index on log crime rates recorded during the quarter before the interview in, respectively, the LA (columns 1-2) or PFA (columns 3-4) of residence. The GHQ index has been normalized to vary between 0 (least distressed) and 1 (most distressed). "Other individual controls" are: age, age squared, a dummy for children in the household, categorical variables for education level, and log household income.

Sample: BHPS data. Urban LAs.

Standard errors: robust and clustered by LA (upper part of the table; 165 clusters) or by PFA (lower part of the table; 41 clusters); ${ }^{*}$ significant at $10 \% ;{ }^{* *}$ significant at $5 \% ;{ }^{* * *}$ significant at $1 \%$. 
Table AA 3 - Mental health (GHQ) and crime: trends and initial conditions

\begin{tabular}{|c|c|c|c|c|c|c|c|c|c|}
\hline & 1 & 2 & 3 & 4 & 5 & 6 & 7 & 8 & 9 \\
\hline & \multicolumn{9}{|c|}{ LA crime } \\
\hline \multirow[b]{2}{*}{$\log$ (violent crime rate) } & $\begin{array}{l}0.008^{* *} \\
{[0.004]}\end{array}$ & $\begin{array}{l}0.007^{*} \\
{[0.004]}\end{array}$ & $\begin{array}{c}0.007 \\
{[0.004]}\end{array}$ & $\begin{array}{l}0.008^{\star *} \\
{[0.004]}\end{array}$ & $\begin{array}{l}0.008^{* *} \\
{[0.004]}\end{array}$ & $\begin{array}{l}0.007^{*} \\
{[0.004]}\end{array}$ & $\begin{array}{l}0.007^{*} \\
{[0.004]}\end{array}$ & $\begin{array}{l}0.007^{*} \\
{[0.004]}\end{array}$ & $\begin{array}{c}0.006 \\
{[0.004]}\end{array}$ \\
\hline & 0.001 & 0.001 & 0.001 & 0.002 & 0.001 & 0.001 & 0.002 & 0.001 & 0.001 \\
\hline \multirow{4}{*}{$\log$ (property crime rate) } & [0.003] & {$[0.003]$} & [0.003] & [0.003] & [0.003] & {$[0.003]$} & [0.003] & [0.003] & [0.003] \\
\hline & $0.008^{* *}$ & $0.007^{*}$ & $0.007^{*}$ & $0.009^{* *}$ & $0.008^{* *}$ & $0.007^{*}$ & $0.007^{*}$ & $0.007^{*}$ & 0.006 \\
\hline & {$[0.004]$} & {$[0.004]$} & {$[0.004]$} & {$[0.004]$} & {$[0.004]$} & {$[0.004]$} & {$[0.004]$} & {$[0.004]$} & {$[0.004]$} \\
\hline & \multicolumn{9}{|c|}{ PFA crime } \\
\hline \multirow[b]{3}{*}{$\log$ (violent crime rate) } & $0.014^{\star \star \star}$ & $0.014^{\star * \star}$ & $0.013^{\text {*** }}$ & $0.015^{* * *}$ & $0.015^{\star \star *}$ & $0.014^{\star \star \star}$ & $0.014^{* *}$ & $0.014^{* *}$ & $0.013^{* *}$ \\
\hline & {$[0.004]$} & {$[0.005]$} & {$[0.005]$} & {$[0.005]$} & {$[0.005]$} & {$[0.005]$} & {$[0.006]$} & {$[0.006]$} & {$[0.006]$} \\
\hline & $0.006^{* *}$ & $0.006^{*}$ & $0.006^{*}$ & $0.006^{* *}$ & $0.006^{* *}$ & 0.005 & 0.005 & 0.005 & 0.005 \\
\hline \multirow{3}{*}{$\log$ (property crime rate) } & {$[0.003]$} & {$[0.003]$} & {$[0.003]$} & {$[0.003]$} & {$[0.003]$} & {$[0.003]$} & [0.003] & {$[0.004]$} & {$[0.004]$} \\
\hline & $0.015^{* * *}$ & $0.015^{\star *}$ & $0.014^{\star *}$ & $0.016^{* * *}$ & $0.016^{* * *}$ & $0.016^{* * *}$ & $0.015^{\star *}$ & $0.015^{* *}$ & $0.015^{* *}$ \\
\hline & {$[0.005]$} & {$[0.006]$} & {$[0.005]$} & {$[0.005]$} & {$[0.005]$} & {$[0.005]$} & [0.006] & {$[0.007]$} & {$[0.007]$} \\
\hline PFA linear trend & & $X$ & & & & & & $X$ & \\
\hline LA linear trend & & & $x$ & & & & & & $x$ \\
\hline Initial LA crime rates & & & & $x$ & $x$ & $x$ & $x$ & $x$ & $x$ \\
\hline Initial avg GHQ (LA) & & & & & $x$ & $x$ & $x$ & $x$ & $x$ \\
\hline Initial avg BHPS controls (LA) & & & & & & $x$ & $x$ & $x$ & $x$ \\
\hline Initial LA controls & & & & & & & $x$ & $x$ & $x$ \\
\hline Individual controls & $\mathrm{X}$ & $\bar{X}$ & $\mathrm{X}$ & $\bar{X}$ & $\bar{X}$ & $\bar{X}$ & $\mathrm{X}$ & $\mathrm{X}$ & $\mathrm{X}$ \\
\hline Year-quarter dummies & $x$ & $x$ & $x$ & $x$ & $x$ & $x$ & $x$ & $x$ & $x$ \\
\hline All LA controls & X & $x$ & $x$ & 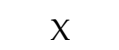 & $\mathrm{X}$ & $x$ & $x$ & $x$ & $x$ \\
\hline Observations & 25,647 & 25,647 & 25,647 & 25,647 & 25,635 & 25,635 & 24,661 & 24,661 & 24,661 \\
\hline
\end{tabular}

Note. This table reports FD estimates of GHQ index on log crime rates recorded during the quarter before the interview in, respectively, the LA (upper part of the table) or PFA (lower part of the table) of residence. The GHQ index has been normalized to vary between 0 (least distressed) and 1 (most distressed). A linear trend is included at the PFA level (columns 2 and 8 ) or at the LA level (columns 3 and 9). "Initial LA crime rates" is the average crime rate (respectively, total, property and violent) in the LA of residence in year 2002 interacted with year dummies. "Initial avg GHQ (LA)" is the average GHQ in the LA of residence measured over the period 1999-2001 and interacted with year dummies. "Initial avg BHPS controls (LA)" are the averages of individual controls in the LA of residence measured over the period 1999-2001 and interacted with year dummies. "Initial LA controls" are the average LA controls measured over the period 1999-2001 and interacted with year dummies. Other controls are: individual controls (age, age squared, a dummy for children in the household, dummies for marital status, for employment status and for education level, and log household income); a full set of year-quarter dummies; employment rate in the LA of residence (yearly average); all LA controls (employment rate, share of residents receiving welfare benefits, share of individuals aged 15-24 over total adult population, immigrants share, number of policemen per capita and log population size). Each cell reports results from a separate regression, with total crime, violent crime and property crime included alternatively in the regression.

Sample: BHPS data. Urban LAs.

Standard errors: robust and clustered by LA (upper part of the table; 165 clusters) or by PFA (lower part of the table; 41 clusters); *significant at 10\%; **significant at $5 \%$; $* * *$ significant at $1 \%$. 


\begin{tabular}{|c|c|c|c|c|c|c|c|c|}
\hline GHQ item: & $\begin{array}{l}\text { 1) Unable to } \\
\text { concentrate }\end{array}$ & $\begin{array}{l}\text { 3) Playing } \\
\text { useful role }\end{array}$ & $\begin{array}{l}\text { 5) Constantly } \\
\text { under strain }\end{array}$ & $\begin{array}{l}\text { 6) Unable to } \\
\text { overcome } \\
\text { difficulties }\end{array}$ & $\begin{array}{l}\text { 7) Enjoy day- } \\
\text { to-day } \\
\text { activities }\end{array}$ & $\begin{array}{l}\text { 9) Feeling } \\
\text { unhappy or } \\
\text { depressed }\end{array}$ & $\begin{array}{l}\text { 11) Feeling } \\
\text { worthless }\end{array}$ & $\begin{array}{l}\text { 12) Not feeling } \\
\text { reasonably } \\
\text { happy }\end{array}$ \\
\hline \multirow[t]{2}{*}{$\log$ (total crime rate) } & $0.017^{*}$ & $0.017^{* *}$ & $0.016^{* *}$ & $0.021^{* * *}$ & $0.017^{* *}$ & $0.022^{* *}$ & $0.012^{*}$ & $0.016^{* *}$ \\
\hline & {$[0.008]$} & {$[0.008]$} & {$[0.007]$} & {$[0.007]$} & {$[0.007]$} & {$[0.010]$} & {$[0.007]$} & {$[0.006]$} \\
\hline \multirow[t]{2}{*}{$\log$ (violent crime rate) } & 0.005 & 0.005 & 0.004 & $0.011^{* *}$ & 0.006 & $0.011^{* *}$ & $0.007^{* *}$ & $0.008^{* *}$ \\
\hline & {$[0.005]$} & {$[0.004]$} & [0.005] & {$[0.004]$} & {$[0.004]$} & {$[0.005]$} & [0.003] & {$[0.003]$} \\
\hline \multirow[t]{2}{*}{$\log$ (property crime rate) } & $0.020^{* *}$ & $0.019 * *$ & $0.019^{* *}$ & $0.020^{* *}$ & $0.017^{* *}$ & $0.023^{*}$ & 0.011 & $0.014^{* *}$ \\
\hline & [0.009] & {$[0.008]$} & {$[0.008]$} & [0.009] & {$[0.008]$} & [0.012] & [0.008] & [0.007] \\
\hline Individual controls & $\mathrm{X}$ & $X$ & $\mathrm{X}$ & $X$ & $\mathrm{X}$ & $\mathrm{X}$ & $\mathrm{X}$ & $\mathrm{X}$ \\
\hline Year-quarter dummies & $X$ & $X$ & $X$ & $X$ & $X$ & $X$ & $X$ & $X$ \\
\hline All LA controls & $X$ & $X$ & $X$ & $x$ & $X$ & $X$ & $X$ & $X$ \\
\hline Observations & 25,647 & 25,647 & 25,647 & 25,647 & 25,647 & 25,647 & 25,647 & 25,647 \\
\hline
\end{tabular}

Note. This table reports FD estimates of single GHQ items on log crime rates recorded during the quarter before the interview in the PFA of residence. Each of the GHQ items has been normalized to vary between 0 (least distressed) and 1 (most distressed). Other controls are: individual controls (age, age squared, a dummy for children in the household, dummies for marital status, for employment status and for education level, and log household income); a full set of year-quarter dummies; employment rate in the LA of residence (yearly average); all LA controls (employment rate, share of residents receiving welfare benefits, share of individuals aged 15-24 over total adult population, immigrants share, number of policemen per capita and log population size). Each cell reports estimation results from a separate regression.

Sample: BHPS data. Urban LAs.

Standard errors: robust and clustered by PFA (41 clusters); *significant at $10 \%$; **significant at $5 \%$; ***significant at $1 \%$. 
Table AA 5 - Mental health and crime: different crime types - FD estimator

\begin{tabular}{|c|c|c|c|c|c|c|}
\hline & & & 1 & 2 & 3 & 4 \\
\hline & & & $\begin{array}{l}\text { GHQ - } \\
\text { Overall }\end{array}$ & $\begin{array}{c}\text { GHQ - } \\
\text { Anxiety and } \\
\text { Depression }\end{array}$ & $\begin{array}{c}\text { GHQ - } \\
\text { Social } \\
\text { Dysfunction }\end{array}$ & $\begin{array}{c}\text { GHQ - } \\
\text { Confidence } \\
\text { Loss }\end{array}$ \\
\hline \multirow{10}{*}{ 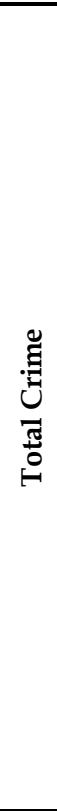 } & \multirow{3}{*}{ 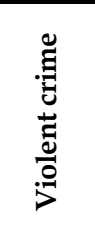 } & ln (Robbery rate) & $\begin{array}{c}0.003 \\
{[0.005]}\end{array}$ & $\begin{array}{c}0.008 \\
{[0.008]}\end{array}$ & $\begin{array}{l}-0.001 \\
{[0.005]}\end{array}$ & $\begin{array}{c}0.003 \\
{[0.010]}\end{array}$ \\
\hline & & ln (Sexual crime rate) & $\begin{array}{l}-0.000 \\
{[0.003]}\end{array}$ & $\begin{array}{c}0.001 \\
{[0.003]}\end{array}$ & $\begin{array}{l}-0.002 \\
{[0.003]}\end{array}$ & $\begin{array}{c}0.002 \\
{[0.004]}\end{array}$ \\
\hline & & In (Violence rate) & $\begin{array}{l}0.005^{* *} \\
{[0.002]}\end{array}$ & $\begin{array}{l}0.007^{* *} \\
{[0.003]}\end{array}$ & $\begin{array}{c}0.003 \\
{[0.003]}\end{array}$ & $\begin{array}{l}0.005^{* *} \\
{[0.002]}\end{array}$ \\
\hline & \multirow{5}{*}{ 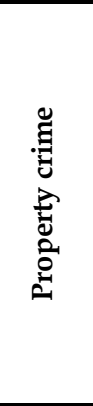 } & ln (Burglary rate) & $\begin{array}{l}0.012^{* *} \\
{[0.004]}\end{array}$ & $\begin{array}{l}0.017^{* *} \\
{[0.006]}\end{array}$ & $\begin{array}{l}0.010^{* *} \\
{[0.004]}\end{array}$ & $\begin{array}{c}0.005 \\
{[0.006]}\end{array}$ \\
\hline & & ln (Criminal Damage rate) & $\begin{array}{l}0.006^{*} \\
{[0.003]}\end{array}$ & $\begin{array}{c}0.007 \\
{[0.005]}\end{array}$ & $\begin{array}{c}0.005 \\
{[0.003]}\end{array}$ & $\begin{array}{c}0.006 \\
{[0.005]}\end{array}$ \\
\hline & & In (Fraud and Forgery rate) & $\begin{array}{c}0.004 \\
{[0.003]}\end{array}$ & $\begin{array}{c}0.005 \\
{[0.005]}\end{array}$ & $\begin{array}{c}0.003 \\
{[0.002]}\end{array}$ & $\begin{array}{c}0.005 \\
{[0.005]}\end{array}$ \\
\hline & & In (Vehicle Crime rate) & $\begin{array}{l}0.008^{* *} \\
{[0.004]}\end{array}$ & $\begin{array}{c}0.010 \\
{[0.006]}\end{array}$ & $\begin{array}{l}0.008^{*} \\
{[0.004]}\end{array}$ & $\begin{array}{c}0.003 \\
{[0.007]}\end{array}$ \\
\hline & & In (Other Theft rate) & $\begin{array}{l}0.014^{* *} \\
{[0.005]}\end{array}$ & $\begin{array}{l}0.019^{* *} \\
{[0.007]}\end{array}$ & $\begin{array}{l}0.013^{* *} \\
{[0.005]}\end{array}$ & $\begin{array}{c}0.005 \\
{[0.007]}\end{array}$ \\
\hline & \multirow{2}{*}{ 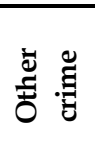 } & In (Drug crime rate) & $\begin{array}{c}0.001 \\
{[0.002]}\end{array}$ & $\begin{array}{c}0.001 \\
{[0.003]}\end{array}$ & $\begin{array}{c}0.001 \\
{[0.003]}\end{array}$ & $\begin{array}{c}0.001 \\
{[0.004]}\end{array}$ \\
\hline & & In (Any other crime rate) & $\begin{array}{c}0.004 \\
{[0.003]}\end{array}$ & $\begin{array}{c}0.006 \\
{[0.004]}\end{array}$ & $\begin{array}{c}0.001 \\
{[0.003]}\end{array}$ & $\begin{array}{l}0.008^{* *} \\
{[0.004]}\end{array}$ \\
\hline & & Individual controls & $\mathrm{X}$ & $\mathrm{X}$ & $X$ & $\mathrm{X}$ \\
\hline & & Year-quarter dummies & $x$ & $X$ & $x$ & $x$ \\
\hline & & all LA controls & $x$ & $x$ & $x$ & $x$ \\
\hline & & bservations & 25,647 & 25,647 & 25,647 & 25,647 \\
\hline
\end{tabular}

Note. This table reports FD estimates of the four GHQ indices (Overall, Anxiety and Depression, Social Dysfunction; Confidence Loss) on log crime rates recorded during the quarter before the interview in the PFA of residence. All four GHQ indices have been normalized to vary between 0 (least distressed) and 1 (most distressed). Other controls are: individual controls (age, age squared, a dummy for children in the household, dummies for marital status, for employment status and for education level, and log household income); a full set of year-quarter dummies; employment rate in the LA of residence (yearly average); all LA controls (employment rate, share of residents receiving welfare benefits, share of individuals aged 15-24 over total adult population, immigrants share, number of policemen per capita and log population size). Each cell reports estimation results from a separate regression.

Sample: BHPS data. Urban LAs.

Standard errors: robust and clustered by PFA (41 clusters); *significant at $10 \%$; **significant at $5 \%$; ***significant at $1 \%$.

Table AA 6 - BHPS: number of interviews by year and month

\begin{tabular}{|c|c|c|c|c|c|c|}
\hline Interview Month & Year 2004 & Wave & Year 2005 & Wave & Year 2006 & Wave \\
\hline January & 84 & 14 & 167 & 15 & 131 & 16 \\
\hline February & 42 & 14 & 58 & 15 & 23 & 16 \\
\hline March & 17 & 14 & 12 & 15 & 19 & 16 \\
\hline April & 9 & 14 & 6 & 15 & 1 & 16 \\
\hline May & 0 & 14 & 3 & 15 & 0 & 16 \\
\hline Total (Jan-May) & 152 & & 246 & & 174 & \\
\hline September & 4,168 & 15 & 4,952 & 16 & 5,226 & 17 \\
\hline October & 3,196 & 15 & 3,064 & 16 & 2,976 & 17 \\
\hline November & 1,291 & 15 & 931 & 16 & 789 & 17 \\
\hline December & 272 & 15 & 176 & 16 & 127 & 17 \\
\hline Total (Sept-Dec) & 8,927 & & 9,123 & & 9,118 & \\
\hline
\end{tabular}

Note. Authors' calculations from BHPS data. 


\section{Online appendix - Alternative channels and further results}

\section{B1 An instrumental variable strategy to deal with movers}

Throughout the paper we have dealt with mobility by treating interviewees as a different individual in each area of residence, with a different individual fixed effect, and by using only the observations when the respondent has spent two consecutive periods in the same area. As discussed above, mobility is very limited (and crime-related mobility in particular) in our data, especially when PFA area rather than LA are considered in the empirical analysis. Nevertheless, to check the robustness of our results, we have followed an alternative approach. We estimate equation $(1 \mathrm{~A})$ in appendix $\mathrm{A} 2$ without treating individuals who move as different individuals in each location, and using all available observations. Moreover, we use an IV strategy, where we instrument the crime rate to which movers are exposed to with the contemporaneous crime rate in the area where they resided in the first wave.

\section{B1.1 Identification}

We now show that using crime rates in the initial location of residence (i.e. LA where the respondents live in 2002, that is, at the beginning of our observation period) as instrument for actual crime rates leads to unbiased estimates, under the plausible assumption that crime in one LA is not correlated with the area fixed effect from a mental distress equation in another local authority. To see this, we define the initial area of residence as $\tilde{r}$, and denote by $\widetilde{C R}_{\tilde{r} t}$ the crime rate in area $\tilde{r}$ at time $t$. As before, in each period, $r$ and $r^{\prime}$ identify, respectively, the initial area of residence and the area of residence in the following period (whenever different from the previous one). Suppose we instrument $\Delta C R_{r t}$ with $\Delta \widetilde{C R}_{\tilde{r} t}$. For individuals who did not move, the instrument is identical to the original variable. We can check the exclusion restriction to assess the validity of this instrument (maintaining that $\left.\operatorname{cov}\left(\Delta \widetilde{C R}_{\tilde{r} t}, \Delta u_{i r(i, t) t}\right)=0\right)$ :

$$
\begin{aligned}
\operatorname{cov}\left(\widetilde{C R}_{\tilde{r} t}-\widetilde{C R}_{\tilde{r} t-1}, \varepsilon_{i r^{\prime}(i, t) t}-\varepsilon_{i r(i, t-1) t-1}\right)=\operatorname{cov}\left(\widetilde{C R}_{\tilde{r} t}-\widetilde{C R}_{\tilde{r} t-1}, L A_{r^{\prime}(i, t)}-L A_{r(i, t-1)}\right) \\
=\operatorname{cov}\left(\widetilde{C R}_{\tilde{r} t}, L A_{r^{\prime}(i, t)}\right)-\operatorname{cov}\left(\widetilde{C R}_{\tilde{r} t}, L A_{r(i, t-1)}\right)-\operatorname{cov}\left(\widetilde{C R}_{\tilde{r} t-1}, L A_{r^{\prime}(i, t)}\right) \\
+\operatorname{cov}\left(\widetilde{C R}_{\tilde{r} t-1}, L A_{r(i, t-1)}\right)
\end{aligned}
$$

Now consider three groups:

- Non-movers. For these individuals, $\tilde{r}=r=r^{\prime}$, and the FD transformation removes the LA fixed effect. Hence $\operatorname{cov}\left(\widetilde{C R}_{\tilde{r} t}-\widetilde{C R}_{\tilde{r} t-1}, \varepsilon_{i r^{\prime}(i, t) t}-\varepsilon_{i r(i, t-1) t-1}\right)=0$ 
- Individuals who moved for the first time away from their initial location. For these individuals, $\tilde{r}=r$ and, therefore, $\left(\widetilde{C R}_{\tilde{r} t}-\widetilde{C R}_{\tilde{r} t-1}\right)=\left(C R_{r t}-C R_{r t-1}\right)$. Hence:

$$
\begin{aligned}
\operatorname{cov}\left(\widetilde{C R}_{r t}-\widetilde{C R}_{r t-1}, \varepsilon_{i r^{\prime}(i, t) t}-\varepsilon_{i r(i, t-1) t-1}\right)=\operatorname{cov}\left(C R_{r t}-C R_{r t-1}, L A_{r^{\prime}}-L A_{r}\right) \\
=\operatorname{cov}\left(C R_{r t}, L A_{r^{\prime}}\right)-\operatorname{cov}\left(C R_{r t}, L A_{r}\right)-\operatorname{cov}\left(C R_{r t-1}, L A_{r^{\prime}}\right) \\
+\operatorname{cov}\left(C R_{r t-1}, L A_{r}\right)
\end{aligned}
$$

The first and third terms are equal to zero given that there is no reason to expect the realization of crime in one area $(r)$ to be correlated with the area fixed effect of another local authority $\left(r^{\prime}\right)$. As long as the correlation between crime rate in one area and the area fixed effect is constant over time, the second and fourth term are equal to each other but of opposite sign. Thus, that they cancel out, so that the covariance between the change in crime and the change in LA fixed effects is zero.

- $2^{\text {nd }}$ and subsequent moves: $\tilde{r} \neq r \neq r^{\prime}$. Now, all terms in the covariance between the change in crime and the change in LA fixed effects are equal to zero (given that there is no reason to expect the realization of crime in one area to be correlated with the area fixed effect of another local authority).

Therefore, the exclusion restriction holds in all scenarios.

\section{B1.2 Empirical results}

Empirical results of this alternative estimation strategy are reported in Table $B$ 1, where we show IV estimates of the effect of LA and PFA crime rate on the GHQ index and on its three sub-components. In these IV regressions crime rate in the area of residence is instrumented with contemporaneous crime rate in the area where the respondent was residing in the first wave of our observation period. These IV estimates are very similar to those obtained with our main identification strategy (see Table 3 and Table 4).

\section{B2 House prices and home owners}

Our paper looks at the effect of temporary crime shocks on mental distress. House prices should reflect the expected level of crime in an area and should adjust following changes in average crime rates which are perceived as relatively permanent. This is precisely what we observe when areas which were relatively deprived and had high crime rates start gentrifying: the observable increase in house prices reflects expectations of a stable reduction in crime rates in the area. On the contrary, there is no clear theoretical reason to expect house prices to respond to temporary crime shock. 
However, to demonstrate that house prices are not a main channel by which area crime affect individual well-being, we first include house prices as additional control in our regressions and we then investigate whether local crime rates affect home owners differently than tenants.

\section{B2.1 Controlling for house prices}

The main source of house price data at the local authority level in the UK is the HM Land Registry. This data set is based on a record of all residential property transactions made in England and Wales since January 1995, whether with cash or with a mortgage. The Land Registry House Price Index is constructed from these sales data, which is seasonally adjusted and corrects for changes in the quality of housing by using repeated sales (for more details: see Sa, 2011). We have matched each individual in our sample with the Index in the LA (or unitary district/county) of residence in the interview year. ${ }^{47}$

We re-run our main regression of local crime on GHQ and on its three sub-categories, but we now include the log of the Land Registry House Price Index as an additional regressions. As Table B 2 and Table B 3 show, the estimated coefficient on the log house price index is very close to zero, and far from significant in all regressions. Its inclusion in the specification, moreover, does not at all affect the size or the significance of the coefficients of local crime rates.

\section{B2.2 Home-owners and local crime shocks}

Moreover, if the house prices channel were important, we should find that home owners are more affected by crime than tenants. Indeed, if temporary crime shocks affected the value of the property, home owners would have an additional reason to be stressed about crime. IN addition, home owners should report a lower value of their property after crime shocks.

BHSP data allow us to test both statements. Regarding statement (1), we can observe whether the individuals in our sample own the house where they live or not (we consider owners also individuals who are still repaying the mortgage). We construct a dummy variable equal to one if the respondent owns the house and zero otherwise: in our sample, roughly 76 percent of the respondents are classified as "home owners". Then we re-run our main regressions (see Table 3 and Table 4 in the paper) and introduce an interaction term of local crime rate (total, violent, property; LA and PFA level) with the dummy home ownership (we lose about 1 percent of the

\footnotetext{
${ }^{47}$ The Land Registry House Price Index is available for the 36 Metropolitan Districts, the 33 London Boroughs and for 111 Unitary District/County. Each individual in the BHPS sample has been matched with the smallest geographical unit available in the Land Registry data.
} 
estimation sample due to missing values in the home ownership question). A significant coefficient on this interaction term would imply that home owners are differently affected by crime than non-owners. As Table B 4 clearly shows, there is not strong evidence of a differential impact of local crime on home owners: although the coefficient on the interaction term is always positive, it is quite small (0.001) and marginally significant only in some of the regressions. Home owners do not seem to be more affected by crime than tenants.

BHPs data allow us to address also the second statement above. In each wave, home owners are asked to report the value of their property. In our sample, the mean reported property value is GBP 204074.3, with a median equal to GBP 170000 and a standard deviation of GBP 167060.6. Using our main specification, we can therefore replace GHQ measures with (log) reported property value as the dependent variable, and re-run our main regressions (only for the subsample of respondents who own the house where they live and have reported its value; about 75 percent of the original sample). This regression addresses the question whether local temporary crime shocks induce home owners to reduce their evaluation of the property. Table B 5 shows no evidence of this. The estimated coefficient - i.e. the elasticity of self-reported home value to changes in local crime rates - is very small in size and far from significant. Taken together, empirical results in Table B 4 and Table B 5 suggest that local crime shocks do not seem to affect residents by lowering the value of their properties. 
Table B 1 - Mental health and crime: IV estimates - FD estimator

\begin{tabular}{|c|c|c|c|c|}
\hline & 1 & 2 & 3 & 4 \\
\hline & $\begin{array}{l}\text { GHQ - } \\
\text { Overall }\end{array}$ & $\begin{array}{c}\text { GHQ - } \\
\text { Anxiety and } \\
\text { Depression }\end{array}$ & $\begin{array}{c}\text { GHQ - } \\
\text { Social } \\
\text { Dysfunction }\end{array}$ & $\begin{array}{c}\text { GHQ - } \\
\text { Confidence } \\
\text { Loss }\end{array}$ \\
\hline & \multicolumn{4}{|c|}{ LA crime } \\
\hline \multirow[t]{2}{*}{$\log$ (total crime rate) } & $0.008^{\star *}$ & $0.014^{* * *}$ & 0.003 & $0.012^{* *}$ \\
\hline & {$[0.004]$} & {$[0.005]$} & {$[0.004]$} & {$[0.005]$} \\
\hline \multirow[t]{2}{*}{$\log$ (violent crime rate) } & 0.002 & 0.003 & -0.000 & 0.004 \\
\hline & {$[0.003]$} & {$[0.004]$} & {$[0.003]$} & {$[0.003]$} \\
\hline \multirow[t]{3}{*}{$\log$ (property crime rate) } & $0.009^{* *}$ & $0.015^{* * *}$ & 0.003 & $0.011^{*}$ \\
\hline & {$[0.004]$} & {$[0.005]$} & {$[0.004]$} & [0.006] \\
\hline & \multicolumn{4}{|c|}{ PFA crime } \\
\hline \multirow[t]{2}{*}{$\log$ (total crime rate) } & $0.014^{* * *}$ & $0.019 * * *$ & $0.012^{* * *}$ & 0.008 \\
\hline & {$[0.004]$} & {$[0.006]$} & {$[0.004]$} & {$[0.006]$} \\
\hline \multirow[t]{2}{*}{$\log$ (violent crime rate) } & $0.005^{*}$ & $0.008^{* *}$ & 0.004 & 0.004 \\
\hline & [0.003] & {$[0.004]$} & {$[0.003]$} & {$[0.003]$} \\
\hline \multirow[t]{2}{*}{$\log$ (property crime rate) } & $0.015^{* * *}$ & $0.021^{* * *}$ & $0.013^{* * *}$ & 0.008 \\
\hline & {$[0.004]$} & {$[0.007]$} & {$[0.004]$} & [0.007] \\
\hline Individual controls & $x$ & $\mathrm{X}$ & $X$ & $X$ \\
\hline Year-quarter dummies & $X$ & $X$ & $x$ & $X$ \\
\hline All LA controls & $X$ & $X$ & $X$ & $X$ \\
\hline IV: F-stat p-value & 0.00 & 0.00 & 0.00 & 0.00 \\
\hline Observations & 26,587 & 26,587 & 26,587 & 26,587 \\
\hline
\end{tabular}

Note. This table reports IV estimates (using a FD estimator) of GHQ index on log crime rates recorded during the quarter before the interview in, respectively, the LA (upper part of the table) and PFA (lower part of the table) of residence. The GHQ index has been normalized to vary between 0 (least distressed) and 1 (most distressed). Other controls are: individual controls (age, age squared, a dummy for children in the household, dummies for marital status, for employment status and for education level, and log household income); a full set of year-quarter dummies; employment rate in the LA of residence (yearly average); all LA controls (employment rate, share of residents receiving welfare benefits, share of individuals aged 15-24 over total adult population, immigrants share, number of policemen per capita and log population size). In these IV regressions crime rate in the area of residence is instrumented with contemporaneous crime rate in the area where the respondent was residing in the first wave of our observation period. Each cell reports estimation results from a separate regression.

Sample: BHPS data. Urban LAs.

Standard errors: robust and clustered by LA (upper part of the table; 165 clusters) or by PFA (lower part of the table; 41 clusters); *significant at $10 \%$; ** significant at $5 \%$; ** significant at $1 \%$. 
Table B 2 - GHQ and local crime - including UK Land Registry House Price Index

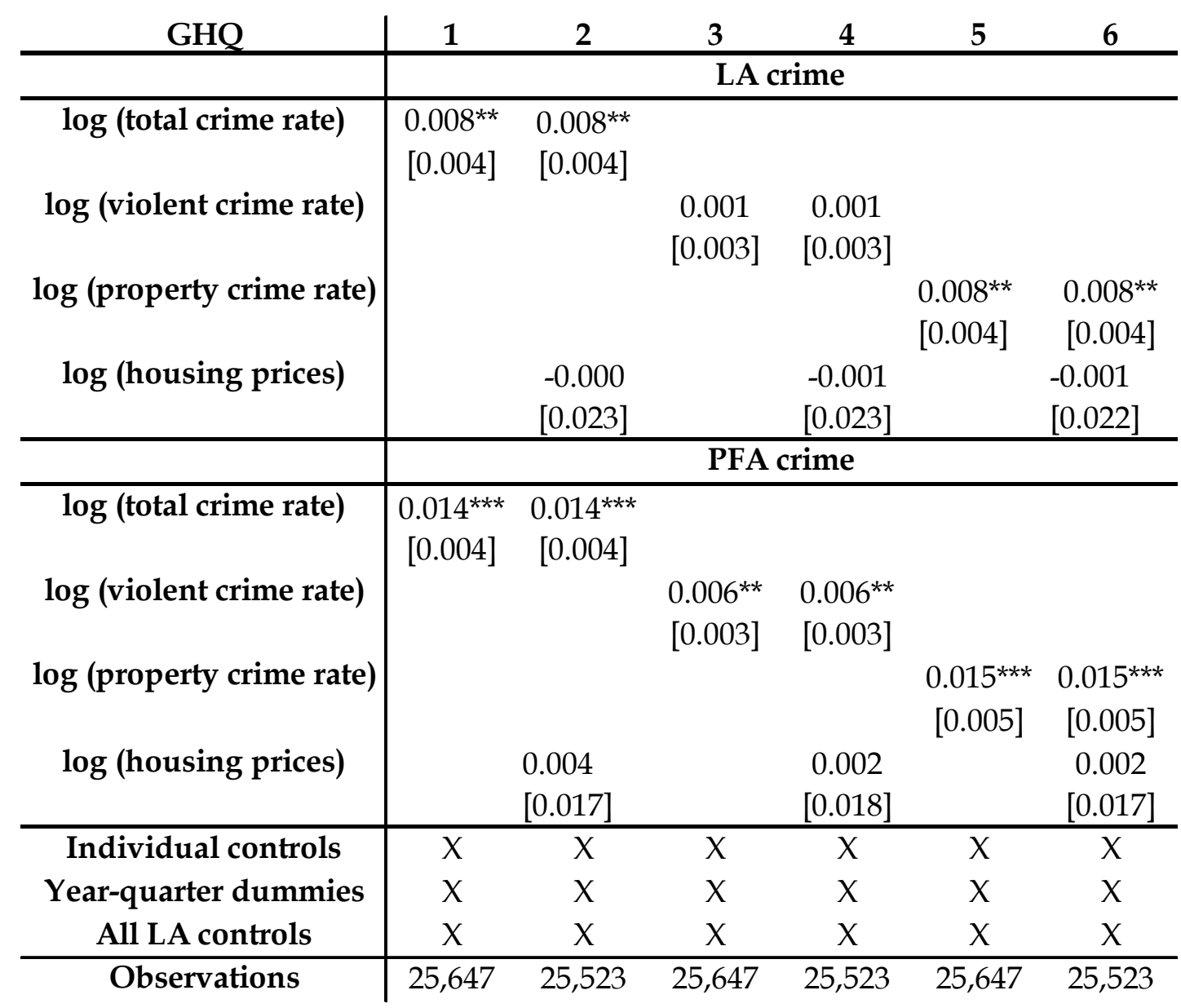

Note. This table reports FD estimates of GHQ index on log crime rates recorded during the quarter before the interview in, respectively, the LA (upper part of the table) or PFA (lower part of the table) of residence. The GHQ index has been normalized to vary between 0 (least distressed) and 1 (most distressed). The variable log(housing prices) is the log of the UK Land Registry House Price Index. Other controls are: individual controls (age, age squared, a dummy for children in the household, dummies for marital status, for employment status and for education level, and log household income); a full set of year-quarter dummies; employment rate in the LA of residence (yearly average); other LA controls (share of residents receiving welfare benefits, share of individuals aged 15-24 over total adult population, immigrants share, number of policemen per capita and log population size).

Sample: BHPS data. Urban LAs. Standard errors: robust and clustered by LA (upper part of the table; 165 clusters) or by PFA (lower part of the table; 41 clusters); ${ }^{*}$ significant at $10 \% ;{ }^{* *}$ significant at $5 \%$; ${ }^{* * *}$ significant at $1 \%$. 


\section{Table B 3 - Subcategories of GHQ and local crime - including UK Land Registry House Price Index}

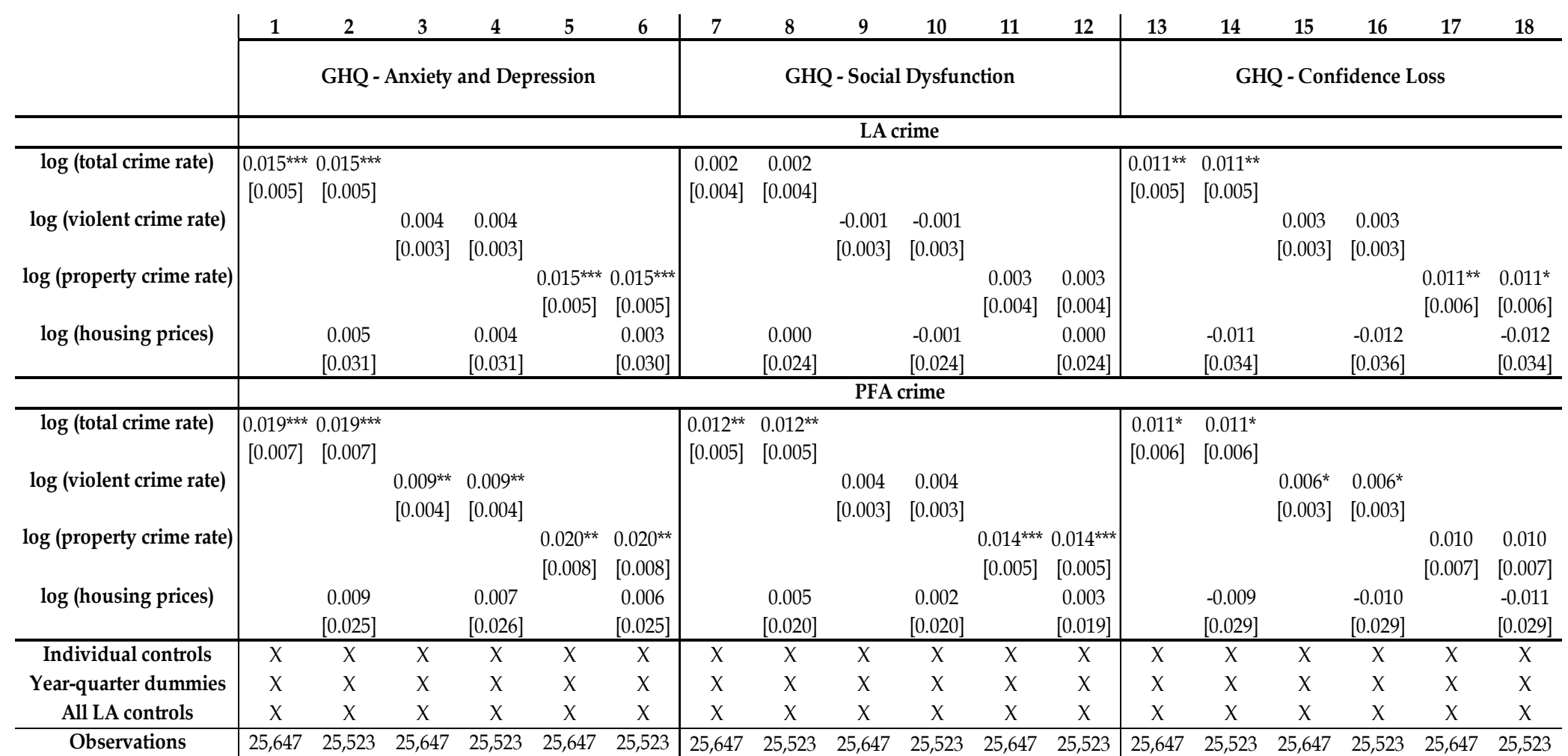

Note. This table reports FD estimates of the four GHQ indices (Overall, Anxiety and Depression, Social Dysfunction; Confidence Loss) on log crime rates recorded during the quarter before the interview in, respectively, the LA (upper part of the table) or PFA (lower part of the table) of residence. All four GHQ indices have been normalized to vary between 0 (least distressed) and 1 (most distressed). The variable log(housing prices) is the log of the UK Land Registry House Price Index. Other controls are: individual controls (age, age squared, a dummy for children in the household, dummies for marital status, for employment status and for education level, and log household income); a full set of year-quarter dummies; employment rate in the LA of residence (yearly average); all LA controls (employment rate, share of residents receiving welfare benefits, share of individuals aged 15-24 over total adult population, immigrants share, number of policemen per capita and log population size). Each row reports results from a separate regression, with total crime, violent crime and property crime included alternatively in the regression. Sample: BHPS data. Urban LAs. Standard errors: robust and clustered by LA (upper part of the table; 165 clusters) or by PFA (lower part of the table; 41 clusters); *significant at $10 \%$; ${ }^{* *}$ significant at $5 \%$; ${ }^{* * *}$ significant at $1 \%$. 
Table B 4 - Heterogeneous effect of local crime: home owners Vs tenants

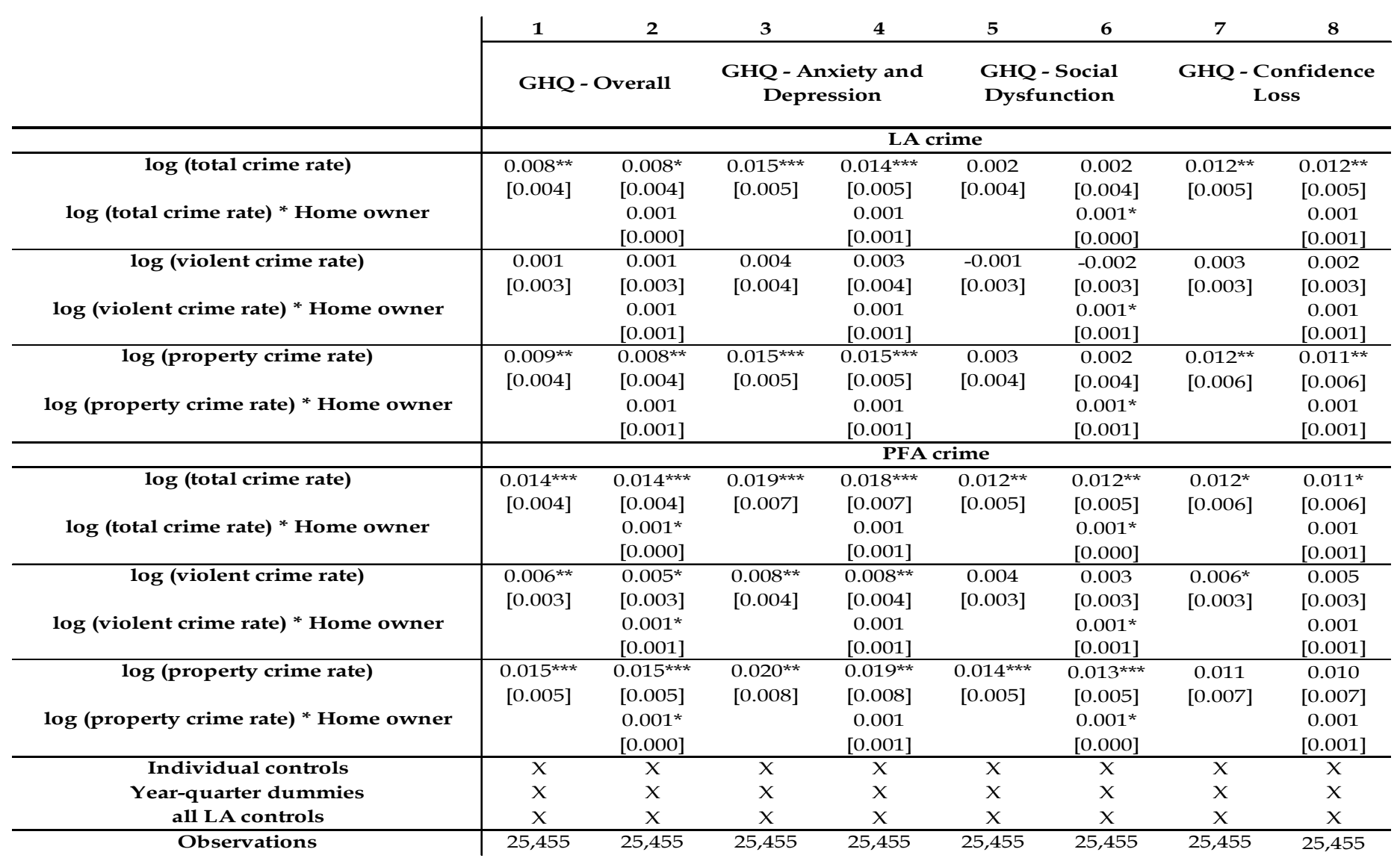

Note. This table reports FD estimates of the four GHQ indices (Overall, Anxiety and Depression, Social Dysfunction; Confidence Loss) on log crime rates recorded during the quarter before the interview in, respectively, the LA (upper part of the table) or PFA (lower part of the table) of residence. All four GHQ indices have been normalized to vary between 0 (least distressed) and 1 (most distressed). Other controls are: individual controls (age, age squared, a dummy for children in the household, dummies for marital status, for employment status and for education level, and log household income); a full set of year-quarter dummies; employment rate in the LA of residence (yearly average); all LA controls (employment rate, share of residents receiving welfare benefits, share of individuals aged 15-24 over total adult population, immigrants share, number of policemen per capita and log population size). Total crime, violent crime and property crime (and their respective interactions) are included alternatively in the regression.

Sample: BHPS data. Urban LAs. Standard errors: robust and clustered by LA (upper part of the table; 165 clusters) or by PFA (lower part of the table; 41 clusters); ${ }^{*}$ significant at $10 \%$; ${ }^{* *}$ significant at $5 \%$; $* * *$ significant at $1 \%$. 
Table B 5 - Reported house value and local crime

\begin{tabular}{c|ccc|ccc}
\multirow{2}{*}{$\log$ (reported house value) } & $\mathbf{1}$ & $\mathbf{2}$ & $\mathbf{3}$ & $\mathbf{4}$ & $\mathbf{5}$ & $\mathbf{6}$ \\
\cline { 2 - 7 } $\log$ (total crime rate) & \multicolumn{7}{c}{ LA } & & \multicolumn{3}{c}{ PFA } \\
& -0.012 & & & -0.020 \\
& {$[0.011]$} & & & {$[0.022]$} & \\
$\log$ (violent crime rate) & & 0.002 & & & -0.002 \\
& & {$[0.007]$} & & & {$[0.015]$} \\
$\log$ (property crime rate) & & & -0.010 & & & -0.024 \\
& & & {$[0.010]$} & & & {$[0.022]$} \\
\hline Individual controls & $X$ & $X$ & $X$ & $X$ & $X$ & $X$ \\
Year-quarter dummies & $X$ & $X$ & $X$ & $X$ & $X$ & $X$ \\
Other LA controls & $X$ & $X$ & $X$ & $X$ & $X$ & $X$ \\
\hline Observations & 19,843 & 19,843 & 19,843 & 19,843 & 19,843 & 19,843
\end{tabular}

Note. This table reports FD estimates of log reported house value on log crime rates recorded during the quarter before the interview in, respectively, the or PFA of residence. Other controls are: individual controls (age, age squared, a dummy for children in the household, dummies for marital status, for employment status and for education level, and log household income); a full set of year-quarter dummies; employment rate in the LA of residence (yearly average); all LA controls (employment rate, share of residents receiving welfare benefits, share of individuals aged 15-24 over total adult population, immigrants share, number of policemen per capita and log population size).

Sample: BHPS data. Urban LAs.

Standard errors: robust and clustered by LA (columns 1-3; 165 clusters) or by PFA (columns 4-6; 41 clusters); *significant at 10\%; **significant at 5\%; ${ }^{* * *}$ significant at $1 \%$. 